\title{
Reliability of position and mobility of the first ray in experienced and inexperienced examiners
}

\author{
Crystal Shirk \\ West Virginia University
}

Follow this and additional works at: https://researchrepository.wvu.edu/etd

\section{Recommended Citation}

Shirk, Crystal, "Reliability of position and mobility of the first ray in experienced and inexperienced examiners" (2004). Graduate Theses, Dissertations, and Problem Reports. 1997.

https://researchrepository.wvu.edu/etd/1997

This Thesis is protected by copyright and/or related rights. It has been brought to you by the The Research Repository @ WVU with permission from the rights-holder(s). You are free to use this Thesis in any way that is permitted by the copyright and related rights legislation that applies to your use. For other uses you must obtain permission from the rights-holder(s) directly, unless additional rights are indicated by a Creative Commons license in the record and/ or on the work itself. This Thesis has been accepted for inclusion in WVU Graduate Theses, Dissertations, and Problem Reports collection by an authorized administrator of The Research Repository @ WVU. For more information, please contact researchrepository@mail.wvu.edu. 


\title{
Reliability of Position and Mobility of the First Ray in Experienced and Inexperienced Examiners
}

Crystal Shirk, BS, ATC

\author{
Thesis submitted to the \\ School of Physical Education \\ at West Virginia University \\ in partial fulfillment of the requirements \\ for the degree of
}

\author{
Master of Science \\ in \\ Athletic Training \\ Michelle A. Sandrey, PhD, ATC, Chair \\ Mia Erickson, EdD, ATC, PT \\ Suzan Ayers, $\mathrm{PhD}$
}

School of Physical Education

Morgantown, WV

2004

Key Words: Foot biomechanics, Foot examination, Manual measurements

Copyright 2004 Crystal Shirk 


\author{
ABSTRACT \\ Reliability of Position and Mobility of the First Ray in \\ Experienced and Inexperienced Examiners.
}

Crystal Shirk, BS, ATC

Context: The first ray is an essential part of the gait cycle and manual measurements of the first ray are a common part of a biomechanical examination. Problems with first ray position or mobility may lead to stress fractures, hallux valgus, metatarsalgia, acquired flatfoot, tendonitis, and plantar ulcerations. Although this measurement is quite common, little research has been completed on the reliability of this measurement. Objective: The purpose of this study is to determine intra and interrater reliability for Root's method for measuring first ray position and mobility for experienced and inexperienced examiners. Design: This study is a single-blind prospective reliability study. Setting: The study took place at HealthWorks Rehab \& Fitness in Morgantown, WV. Patients and Other Participants: A total of 36 subjects volunteered for this study. A total of four examiners were utilized. Two were inexperienced (I1 \& I2), having less than two years of experience working as a certified athletic trainer, and two were experienced (E1 \& E2), having more than six years of experience working as a certified athletic trainer or physical therapist. A total of five recorders volunteered to record data for each examiner.

Interventions: All subjects signed up for two time periods on two different days. Subjects were assigned a different letter as a code with only the principal investigator aware of the identity of the subject. Prior to data collection, examiners were shown Root's technique for measuring first ray position and mobility and practiced for twenty minutes. Examiners were detained in a room while subjects were positioned by the principal investigator in a supine position on treatment tables. A curtain was pulled around the table to blind the examiner from the subjects. After all subjects were positioned, the four examiners entered the room. The right foot's first ray was examined following Root's technique for position and mobility and the results were reported to the examiner's recorder. The examiner then moved to the right of the subject to evaluate the right foot of the next subject. This process was repeated until all right feet were evaluated. The examiners began again with the first subject they initially assessed and following the same procedures, examined all left feet for first ray position and mobility. Position was assessed as plantarflexed, dorsiflexed, or normal. Mobility was assessed as hypermobile, hypomobile, or normal. After both right and left feet were assessed and results were recorded, examiners retreated back to the holding room. All subjects, examiners, and recorders returned a week later, repeating the same procedures. Main Outcome Measures: The expectations of the study were to determine that experienced examiners would have moderate to high intrarater and interrater reliability for position and mobility while inexperienced examiners would have low to moderate intrarater and interrater reliability for position and mobility. Results: Significant kappa correlations were found in position testing for $\mathrm{I} 2(K=0.235, \mathrm{P} \leq .01)$ and $\mathrm{E} 1(K=0.262, \mathrm{P} \leq .001)$ for intrarater reliability and for $\mathrm{I} 2 \mathrm{xE} 2(K=0.180, \mathrm{P} \leq .05)$ and $\mathrm{I} 1 \mathrm{xI} 2(K=0.142, \mathrm{P} \leq .05)$ on day 2 for interrater reliability. Significant kappa correlations were found in mobility testing for I1 $(K=0.263, \mathrm{P} \leq .01)$ and $\mathrm{I} 2(K=0.181, \mathrm{P} \leq .001)$ for intrarater reliability and for I2xE1 $(K=0.216$, $\mathrm{P} \leq .01)$ on day 2 for interrater reliability. Using a scale by Landis and Koch, inexperienced examiners had poor $(K=0.00)$ to fair $(K=0.235)$ agreement and experienced examiners had slight $(K=0.128)$ to fair $(K=0.262)$ agreement for intrarater reliability of first ray position 
measurements. Inexperienced examiner had slight $(K=0.032 \& 0.142)$ agreement and experienced examiners had poor $(K=0.00)$ to slight $(K=0.105)$ agreement for interrater reliability of first ray position measurements. Experienced examiners had poor $(K=0.00)$ to slight $(K=0.069)$ agreement for intrarater reliability and slight $(K=0.092 \& 0.01)$ agreement for interrater reliability of first ray mobility measurements. Inexperienced examiners had slight $(K=0.181)$ to fair $(K=0.263)$ agreement for intrarater reliability and only slight $(K=0.084 \&$ 0.133 ) agreement for interrater agreement of first ray mobility measurements. Conclusion: This study supports previous research that kappa reliability for first ray position and mobility measurements is low. This measurement is nevertheless a common measurement. Further research is needed to evaluate reliability for first ray manual measurement techniques.

Key Words: Foot biomechanics, Foot examination, Manual measurements 


\section{ACKNOWLEDGEMENTS}

I would like to thank my Almighty God for being there for me always. I know that being here and completing this degree would not have been possible without his constant watch over me.

I would like to thank my husband, Conrad, for being here for me through all of my frustrations and excitements of this project. Without his love, support, and never-ending ideas and opinions, I would not have made it though this. I also thank him for his foot poses in photos used for this study. I love you so much.

I would like to thank my parents and my sisters for their support of my return to school. I thank my father for my persistent personality causing me to continue to challenge myself and I thank my mother for my organizational skills. Thank you both for teaching me to keep a steady head on my shoulder and for always keeping me in check, even though I live so far away now. I love you all so much and would not be who I am today without you.

I would like to thank my examiners Ray Adams, MS, PT, ATC, Kevin Kotsko, MS, ATC, Suzanne Bologa, ATC, and Charis Mitchell, ATC for assisting in the crucial portion of this study. I thank you for agreeing to volunteer for this study and for making it to and through this study. I could not have had better examiners to get through the data collection.

I would like to thank Danielle Bifulco, ATC, Scott Dietrich, MS, ATC, Tim Kent, ATC, Kim Samson, ATC, and Matt Wallace, ATC for help with recording data for this study. You were always on top of things and helping me keep my mind straight.

I would like to thank all subjects for coming in on two very cold and snowy mornings to help with the collection of my data. I greatly appreciate your time and effort, because without your help, I would not have had enough subjects.

I would like to thank Dr. Michelle Sandrey for your help with this project. Thank you for accepting me into WVU on a hope that I would swim rather than sink. Without your neverending challenges, I may have never chosen and continued to pursue this route. I appreciate your constant faith, patience, guidance, and criticism throughout this entire process. I feel that I have found something that I may be good at and appreciate everything you've done.

I would like to thank Dr. Mia Erickson for your ideas for this project. My high respect for your opinion provided me with ambition to do my best. I appreciate your support throughout this process, for without it I might have given up. I appreciate all the time and effort you have sacrificed for this study.

I would like to thank Dr. Suzan Ayers for being on my committee and for your help with critiquing my thesis in its early and final stages. Your criticism was important and was always taken into consideration. I really appreciate your agreeing to be a committee member.

I want to thank HealthWorks Rehab \& Fitness of Morgantown, WV for allowing us to use their facility for this study's data collection. 
TABLE OF CONTENTS

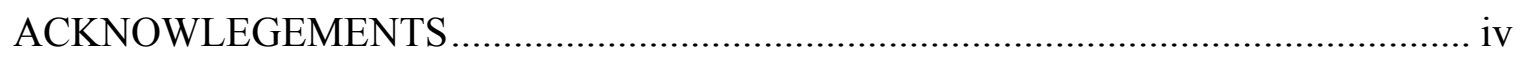

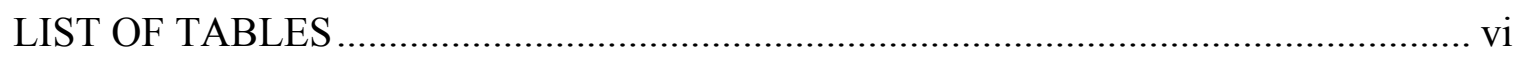

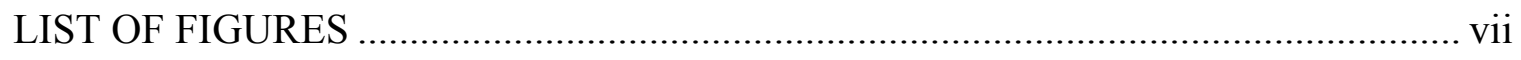

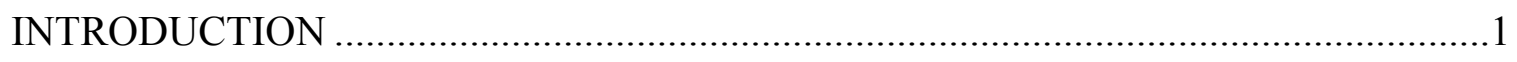

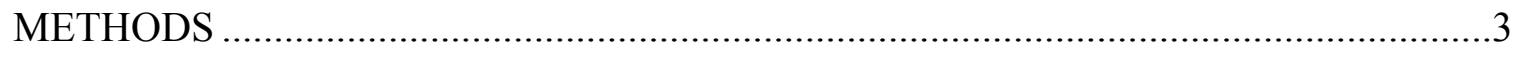

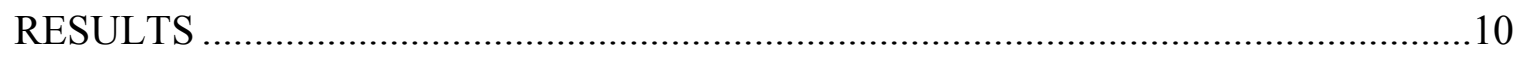

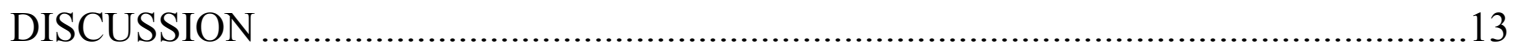

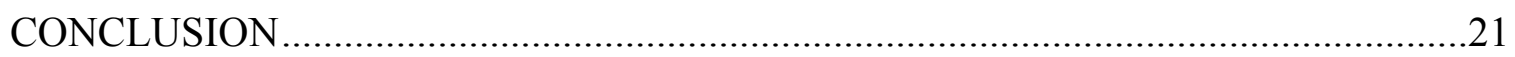

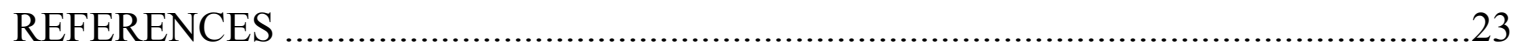

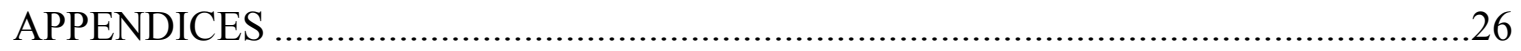

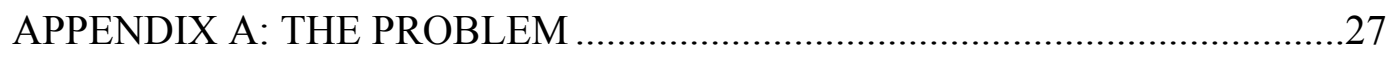

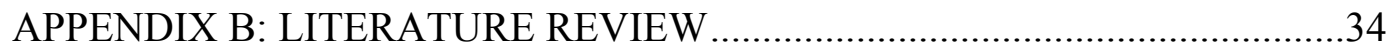

APPENDIX C: ADDITIONAL METHODS .................................................60

APPENDIX D: ADDITIONAL RESULTS .................................................76

APPENDIX E: RECOMMENDATIONS FOR FUTURE RESEARCH .............86

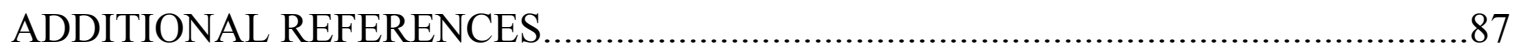




\section{LIST OF TABLES}

Tables

1. Table of Position Intrarater Results for Kmax Explanation......................................10

C1. Informed Consent Form (Examiners) .........................................................60

C2. Informed Consent Form (Recorder) ..............................................................6

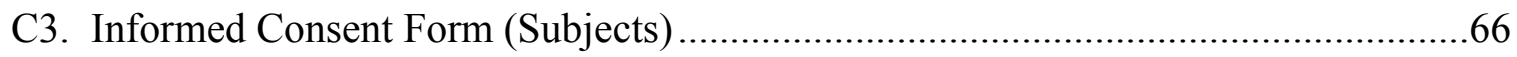

C4. Demographic/Injury History Questionnaire ...................................................69

C5. Procedures for Evaluation of First Ray Position .................................................. 70

C6. Procedures for Evaluation of First Ray Mobility; Root's Technique .......................71

C7. Procedures for Placing the Ankle in Subtalar Joint Neutral...................................71

C8. Recording Sheet for Position and Mobility of the First Ray ..................................72

D1. Intrarater Reliability of First Ray Position Test................................................. 76

D2. Intrarater Distributions for Position Testing ................................................ 76

D3. Interrater Reliability of First Ray Position Test............................................. 77

D4. Interrater Distributions for Position Testing on Day 1 .................................... 78

D5. Interrater Distributions for Position Testing on Day 2 ..................................... 79

D6. Intrarater Reliability of First Ray Mobility Test ..............................................80

D7. Intrarater Distributions for Mobility Testing ................................................ 80

D8. Interrater Reliability of First Ray Mobility Test ............................................ 81

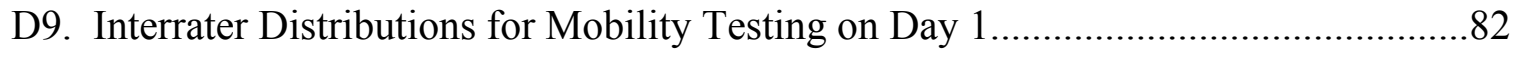

D10.Interrater Distributions for Mobility Testing on Day 2 .....................................83 


\section{LIST OF FIGURES}

Figures

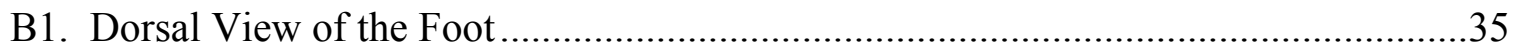

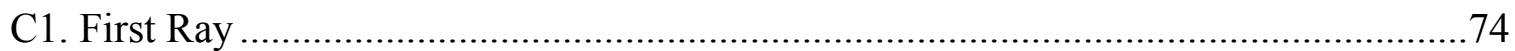

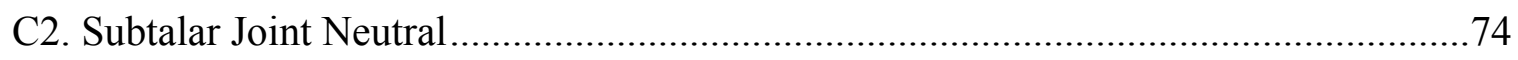

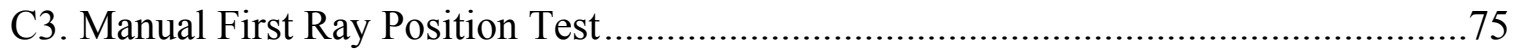

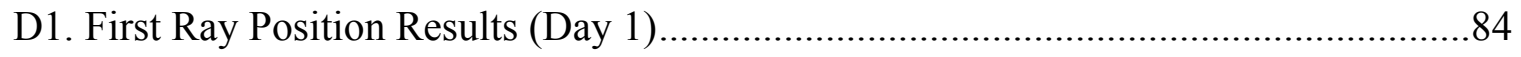

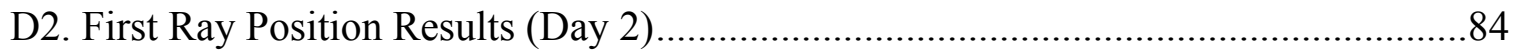

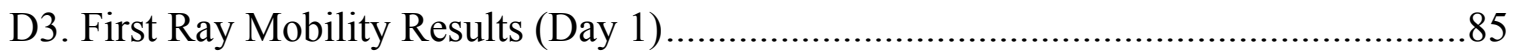

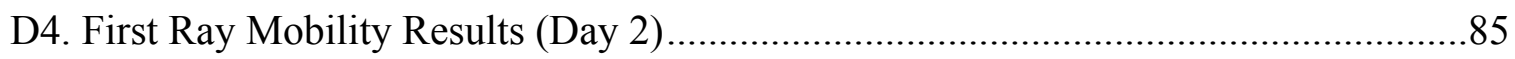




\section{INTRODUCTION}

The first ray is a single unit consisting of the first metatarsal and first cuneiform. ${ }^{1-12}$ As a unit, the first ray serves as an essential element of the foot during the gait cycle. During the gait cycle, the first ray provides shock absorption during the loading response and stability in the terminal stance and pre-swing. Abnormal first ray mobility (hyper or hypomobility) or position (plantarflexion or dorsiflexion) decreases the ability of the first ray to carry out its normal function. Abnormal first ray position or mobility has been reported to alter the foot's biomechanics, causing metatarsalgia, stress fractures, hallux valgus, tendonitis, acquired flatfoot, and plantar ulcerations. ${ }^{1-3,5,7,13-17}$ Abnormal first ray mobility has also been highly correlated to lower extremity measures such as knee rotation and anteroposterior ground reaction forces. ${ }^{18}$ This information gives reason to believe that first ray position and mobility testing are important aspects of the lower extremity examination.

$\operatorname{Root}^{7,8}$ assessed position by observing the level of one thumb when placed under the first ray plantar fat pads in comparison to the other thumb when placed under the lateral four metatarsal plantar fat pads while the foot was in subtalar joint neutral. With no pressure being applied, the first ray was graded as plantarflexed if the first ray was lower than the lateral four metatarsals. It was graded as dorsiflexed if the first ray was higher than the lateral four metatarsals. Finally, it was graded as normal if the first ray was level with the lateral four metatarsals.

While only one technique has been suggested for assessing first ray position ${ }^{7}$, several manual techniques have been suggested for assessing first ray mobility. ${ }^{6,19,20}$ Glasoe $^{19}$ examines mobility by observing the level of the first ray plantar fat pad in 
comparison to the lateral four metatarsal plantar fat pads when dorsal pressure is applied to the first ray and the lateral four metatarsals are stabilized. If the first ray fat pad becomes even with the lateral four metatarsal plantar fat pads, it is graded as normal. If the first ray fat pad elevates higher than the lateral four metatarsals, it is graded as hypermobile. Finally, if the first ray fat pad does not elevate to be even with the lateral four metatarsals, it is graded as hypomobile.

Root $^{7,8}$ assessed mobility by examining first ray plantarflexion and dorsiflexion with the lateral four metatarsals stabilized. If the amount of plantarflexion is equal to the amount of dorsiflexion, the first ray is said to be normal. If more dorsiflexion occurs than plantarflexion, the first ray is said to be hypermobile. If more plantarflexion occurs than dorsiflexion, the first ray is graded as hypomobile.

In addition to manual techniques described above, first ray mobility and position can be performed using radiographs ${ }^{4,8}$ or a first ray mobility measuring device ${ }^{19}$. The reliability of the device designed by Glasoe et al. ${ }^{5}$ was ICC $=0.98$ while validity was found to be $\mathrm{r}=0.97$ when using radiographs as a gold standard. Although the mobility measuring device was reported to be highly reliable in comparison to radiographs, neither the device nor radiographs are readily available or practical in a sports medicine setting.

Manual techniques are more practical and are frequently used in sports medicine settings, but Glasoe et al.' ${ }^{3}$ findings indicate moderate to high intrarater reliability and low interrater reliability using a kappa statistic. Intrarater values were obtained in two testing sessions by an inexperienced physical therapist, an experienced physical therapist, and an experienced surgeon, with kappa results of $K=0.50,0.55$, and 0.85 , respectively. ${ }^{19}$ Interrater reliability was determined by comparing each of the two physical therapist's 
results to the surgeon, with kappa results of $K=0.16$ (experienced) and 0.09

(inexperienced). ${ }^{19}$ These numbers may be low because in this study, neither the therapists nor the surgeon were given an opportunity to practice the technique prior to being used.

Nevertheless, only one reliability study on Glasoe's manual mobility technique exists. In addition, there is no reliability data for the method described by Root, just as there is no research examining reliability for Root's technique for experienced and inexperienced examiners. Furthermore, there is no research providing reliability data for the examination of first ray position. Therefore, the aim of this study is to determine intra and interrater reliability for Root's method for measuring first ray position and mobility for experienced and inexperienced examiners.

\section{METHODS}

The research design was a single-blind prospective reliability study, examining the interrater reliability of experienced and inexperienced examiners for assessing first ray position (plantarflexed, dorsiflexed, or normal) and mobility (hypermobile, hypomobile, or normal). The second part of the study examined test-retest (intrarater) reliability of first ray position and mobility assessment.

Subjects

Examiners and Recorders: This study utilized four examiners. Two of these examiners were labeled inexperienced. In this study inexperienced was defined as a certified athletic trainer or licensed physical therapist with less than two years of clinical experience in their field of study. Two certified athletic trainers (I1 and I2), who were second year graduate athletic training students at West Virginia University and who had completed classes in anatomy and biomechanics, volunteered to serve as the inexperienced 
examiners. The other two examiners were labeled experienced. Experienced was defined as a certified athletic trainer or licensed physical therapist with six or more years of clinical experience in their field and an individual who works with athletes/patients having lower extremity pathology. For this study, experienced testers included one physical therapist/certified athletic trainer (E1) working in the sports medicine clinical setting and one athletic trainer (E2) working in the college setting volunteered for this study. Five recorders volunteered to record all data for both days, allowing the examiners to be blinded to the measurements.

Subjects: The study enrolled a total of 36 subjects $(n=72$ feet) ranging in age from 18 to 39 ( $23 \pm 5.93$ years). There were a total of 22 females and 14 males. A total of 30 (88.9\%) subjects were in the Athletic Training and Physical Education Teacher Education programs at West Virginia University. All subjects were recruited using convenience sampling. The subjects were healthy males and females from a college age population. The only exclusion criteria for these subjects was a history of foot surgery. ${ }^{19}$ All examiners, recorders, and subjects signed an informed consent form (Table C1-3) that was approved by the Institutional Review Board for the Protection of Human Subjects at West Virginia University and completed a demographic and medical history questionnaire (Table C4) prior to the study. Introductory Procedures

Examiners and Recorders: All second year certified athletic trainers in the graduate athletic training program at West Virginia University were contacted about participating in the research study. They were informed of the purpose and methodology of the study and were asked to respond if they were interested in participating in the study as an examiner. 
The first two inexperienced examiners to volunteer were chosen. Five certified athletic trainers from a sports medicine clinic and West Virginia University in the "experienced" category were contacted. The first two experienced examiners to volunteer were chosen. The principal investigator then contacted all first and second year graduate students in the graduate athletic training program at West Virginia University to request recorders for each day. They were informed of the purpose and methodology of the study and were asked to respond if they were interested in participating in the study. The first five recorders to volunteer were chosen.

Subjects: The principal investigator contacted all undergraduate and graduate Athletic Training and Physical Education Teacher Education students at West Virginia University requesting subjects for a research study. They were informed of the purpose and methodology of the study and were asked to sign up if they were interested in participating in the study. During an orientation meeting, an informed consent form and demographic and medical history questionnaire was given out to all potential subjects explaining their rights as research participants. This information was used to determine if any subjects should be excluded. All information was kept confidential using blind coding. Blind coding entailed placing a different letter by each name on the sign-up list, which was used during data collection. The data was only available to the principal investigator. Once subjects were selected, they signed up for any of two time slots for each of the two testing days.

Evaluation Protocol

Prior to testing on Day 1, all examiners were shown Root's ${ }^{8}$ manual method of measuring first ray position and mobility. (Table C5-6) The examiners then practiced 
these methods for twenty minutes until they felt comfortable. The first ray was evaluated with the subject in a supine position and with the ankle in subtalar joint neutral for standardization purposes (Table C7 and Figure C2). The amount of pressure to be placed during mobility testing was explained for standardization purposes.

First ray position: The position of the first ray is determined by how it lies in comparison to the lateral four metatarsals. The examiner places one thumb on the plantar aspect of the first metatarsal head and the opposite thumb on the lateral four metatarsal heads while applying no pressure (Figure C3A). Each thumb should lie just proximal to the distal plantar metatarsal heads. The examiner will then decide if the first ray is in a plantarflexed, dorsiflexed, or normal position. If the first ray is dorsiflexed, the first ray will lie above the level of the lateral four metatarsals (Figure C3B). If the first ray is plantarflexed, the first ray will lie below the level of the lateral four metatarsals (Figure $\mathrm{C} 3 \mathrm{C})$. If the first ray is normal, the first ray will lie at an even level with the lateral four metatarsals.

First ray mobility: To measure first ray mobility, the examiner grasps the first metatarsal with one hand and stabilizes the $2^{\text {nd }}-5^{\text {th }}$ metatarsals with the other hand. The thumbs of both hands should lie just proximal to the distal plantar metatarsal heads. The thumb holding the first metatarsal then dorsiflexed the first ray by producing a dorsal force on the sagittal and frontal plane until the examiner feels an endpoint. The index finger holding the first metatarsal on the head of the metatarsal will then plantarflex the first ray, producing a plantar force on the sagittal and frontal plane until the examiner feels an endpoint. When the amount of dorsiflexion exceeds the amount of plantarflexion, the first ray was graded as hypermobile. When the amount of plantarflexion exceeds the amount of 
dorsiflexion, the first ray was graded as hypomobile. When the amount of plantarflexion was equal to the amount of dorsiflexion, the first ray is graded as normal.

Testing Procedures

Examiners: At the beginning of each allotted time slot, the examiners were taken to a closed room so that they were blinded to the subjects. Once all subjects were positioned they were covered with a curtain so that only the subjects' feet were showing. All four examiners then entered the room and positioned themselves at one subject's right foot to evaluate their first ray. The right foot's first ray was examined following Root's technique for position and mobility and the results were quietly reported to the examiner's recorder. The examiner then moved to the right of the subject to evaluate the right foot of the next subject. This process was repeated until all right feet were evaluated. The examiners began again with the first subject they initially assessed and following the same procedures, examined all left feet for first ray position and mobility. To ensure that the correct foot was measured, a towel was placed over the opposite foot. The right feet of all subjects were evaluated before the left feet were evaluated for standardization purposes to decrease the chance of the examiner recall of right foot measurements on the same subjects and to evaluate each foot as an individual unit. The examiners were blinded to all data. ${ }^{19}$

Subjects: Three to five subjects showed up for each allotted 20-minute time slot. They waited in the lobby until the principal investigator came to bring them back to the treatment area. Five treatment tables spread throughout the treatment area were used. At least one unused treatment table was left between each used treatment table. The principal investigator asked subjects to remove their socks and shoes, roll their pants up to their knees, and to lie down supine on one of five designated treatment tables with their head 
closest to the wall. Subjects were asked to slide down the table to allow their feet and ankles to hang off the end of the table. All treatment tables were separated by a curtain, which was pulled around each treatment table. The end of the pulled curtain was draped across the subject's lower leg to blind the examiner to the subject.

Recorders: Each recorder rotated with their assigned examiner during each testing session to record results before the next evaluation was performed. One data sheet was used for each examiner, with a column for position results and a column for mobility results (Table C8). Results were recorded as: $\mathrm{PF}=$ plantarflexed, $\mathrm{DF}=$ dorsiflexed, Norm $=$ normal Hyper $=$ hypermobile, Hypo $=$ hypomobile. Letters previously chosen by coding were placed on that subject's table for recording purposes. At the end of the day, the completed data sheet was given to the principal investigator.

Test-Retest Procedures

To complete the test-retest (intrarater) portion of this study, all subjects returned for a second evaluation seven days after the first evaluation. ${ }^{19,21}$ The examiners, subjects, and recorders followed the same procedures on the second day as described above for testing day one. Evaluation of first ray position and mobility was repeated.

Statistical Analysis

Descriptive analysis was used to compile the means and standard deviations of the subjects' demographics. Inter and intrarater reliability measures were assessed by a kappa correlation coefficient $(K) .{ }^{22,23}$ The alpha level was set at $\mathrm{P} \leq 0.05$. Intrarater reliability was measured by comparing each tester's results between the two days. An interrater kappa correlation coefficient for the experienced examiners, inexperienced examiners, and for experienced and inexperienced examiners together was also used. Analyses were 
performed using SPSS for Windows statistical software (version 11.0.0, SPSS. Inc., Chicago, IL).

A kappa correlation coefficient was utilized to eliminate the risk of significant results based on chance. ${ }^{22,23}$ This is useful in cases where one examiner has a tendency to use a specific category more often than any other category. A kappa correlation coefficient can be used when certain requirements are met. The units of measurement (first ray position and first ray mobility) are independent, the categories (plantarflexed, dorsiflexed, normal, hypermobile, or hypomobile) are nominal and "independent, mutually exclusive, and exhaustive," and the judges (examiners) operate independently. ${ }^{22}$ To interpret kappa correlation coefficients the following scale by Landis and $\mathrm{Koch}^{24}$ was used: $0.81-1.0=$ almost perfect agreement, $0.61-0.8=$ substantial agreement, $0.41-0.6=$ moderate agreement, $0.21-0.4=$ fair agreement, $0.00-0.2=$ slight agreement, and $<0.0=$ poor agreement.

A percentage of obtained agreement $(P o)$ was calculated by adding the total of agreed data and dividing by the total possible data. ${ }^{22}$ In the case of the low kappa coefficients, maximum kappa coefficient are calculated. ${ }^{22,23}$ The Kmax is the best agreement that can occur without chance given the existing distribution. ${ }^{22,23} \mathrm{~A} K / K \max$ is the proportion of the maximum kappa coefficient that kappa was able to reach. A high $K / K \max$ indicates that two examiners could agree well, factoring out chance. Since $K \max$ indicates the best agreement that can occur with the given distributions, the difference between $K$ and $K \max$ is the amount of disagreement truly present.

To calculate the Kmax, the following formula was used (refer to data in Table 1 for an explanation of the determination of $\mathrm{Kmax}$ ): 


$$
K \max =\frac{P m-P c}{1-P c}
$$

Table 1. Table of position intrarater results for $K \max$ explanation.

\begin{tabular}{|c|c|c|c|c|c|}
\hline \multirow{2}{*}{ E2-Day 1} & \multicolumn{5}{|c|}{ E2-Day 2} \\
\hline & & Plantarflexed & $\overline{\text { Dorsiflexed }}$ & Normal & Total \\
\hline & Plantarflexed & 15 & 6 & 4 & 25 \\
\hline & Dorsiflexed & 18 & 8 & 8 & 34 \\
\hline & Normal & 4 & 2 & 7 & 13 \\
\hline Total & & 37 & 16 & 19 & 72 \\
\hline
\end{tabular}

The first calculation determines $P m$, which is marginal data taken from pairs of column and row totals. The lowest of each pair is chosen and the percentages of each are divided out of the total $(25 / 72,16 / 72$, and $13 / 72)$ and are added together. The result should be $P m=.35+.22+.18=.75$.

The next calculation required is for $P c$, which is "the proportion of units for which agreement is expected by chance."22 To obtain $P c$, multiply the percentage of the total in row $1(25 / 72)$ by the percentage of the total in column $1(37 / 72)$. Do the same for each row/column and total the results. The result should be: $P c=.18+.10+.05=.33$. With these calculations, $K \max$ can be computed. $K \max =\frac{.75-.33}{1-.33}=.626$

\section{RESULTS}

Position

Intrarater reliability of position testing for each examiner ranged from 0.00 to 0.262 . The only statistically significant results existed for examiners $I 2(K=0.235$, $\mathrm{P}=0.002)$ and $\mathrm{E} 1(K=0.262, \mathrm{P}=0.001)$. All other intrarater results for position measurements were not significant. The Po ranged from $42 \%$ (experienced) to $67 \%$ (inexperienced). The $K \max$ for intrarater reliability ranged from 0.28 (inexperienced) to 0.65 (experienced). The $K / K \max$ for intrarater reliability ranged from $0.0 \%$ 
(inexperienced) to $42.7 \%$ (inexperienced). Results for intrarater reliability of first ray position are shown in Tables D1 and D2.

Interrater reliability of position testing for all examiners ranged from 0.00 to 0.180 . Interrater reliability for experienced examiners was 0.105 and 0.00 while for inexperienced examiners it was 0.032 to 0.142 . Interrater reliability ranged from 0.007 to 0.142 on day 1 and ranged from 0.00 to 0.180 on day 2 . Statistically significant results were obtained for I1 and $\mathrm{I} 2(K=0.142, \mathrm{P}=0.025)$ and for $\mathrm{I} 2$ and $\mathrm{E} 2(K=0.180, \mathrm{P}=0.035)$, both occurring on day 2 of data collection. All other interrater results for position measurements were not significant. The $P o$ ranged from $20 \%$ (inexperienced and experienced) to $44 \%$ (inexperienced and inexperienced) on day 1 and from 26\% (experienced and experienced) to $51 \%$ (inexperienced and experienced) on day 2 . The $K \max$ for interrater reliability ranged from 0.11 (inexperienced vs. experienced) to 0.69 (experienced vs. experienced) on day 1 and from 0.30 (inexperienced vs. inexperienced) to 0.86 (inexperienced vs. experienced) on day 2. $K / K \max$ for interrater reliability ranged from $4.4 \%$ (inexperienced vs. experienced) to $38.6 \%$ (inexperienced vs. experienced) on day 1 and from $0.0 \%$ (inexperienced vs. experienced) to $47.3 \%$ (inexperienced vs. inexperienced) on day 2 . Results for interrater reliability of first ray position are shown in Tables D3-D5. Frequencies for position results by examiner on day 1 and day 2 are displayed in Figures D1 and D2.

Mobility

Intrarater reliability of mobility testing for each examiner ranged from 0.00 to 0.263 . The only statistically significant results were obtained for examiners I1 $(K=0.263$, $\mathrm{P}=0.001)$ and $\mathrm{I} 2(K=0.181, \mathrm{P}=0.010)$. All other intrarater results for mobility 
measurements were not significant. The $P o$ ranged from $40 \%$ (experienced) to $57 \%$ (inexperienced). The Kmax for intrarater reliability ranged from 0.48 (inexperienced) to 0.83 (experienced). The $K / K \max$ for intrarater reliability ranged from $0.0 \%$ (experienced) to $50.6 \%$ (inexperienced). Results for intrarater reliability of first ray mobility are shown in Tables D6 and Figure D7.

Interrater reliability of mobility testing for all examiners ranged from 0.00 to 0.216 . Interrater reliability for experienced examiners was 0.092 and 0.010 while for inexperienced examiners it was 0.053 and 0.133 . Interrater reliability ranged from 0.004 to 0.105 on day 1 and ranged from 0.00 to 0.216 on day 2 . Statistically significant results were obtained for examiners $\mathrm{I} 2$ and $\mathrm{E} 1(K=0.216, \mathrm{P}=0.003)$. All other interrater results for mobility measurements were not significant. The $P o$ ranged from $38 \%$ (inexperienced and experienced) to $46 \%$ (inexperienced and inexperienced) on day 1 and from $24 \%$ (inexperienced and experienced) to $46 \%$ (inexperienced and experienced) on day 2 . The Kmax for interrater reliability ranged from 0.54 (inexperienced vs. experienced) to 0.82 (inexperienced vs. experienced) on day 1 and ranged from 0.49 (inexperienced vs. experienced) to 0.85 (experienced vs. experienced) on day 2 . The $K / K \max$ for interrater reliability ranged from $0.5 \%$ (inexperienced vs. experienced) to $18.1 \%$ (inexperienced vs. experienced) on day 1 and from $0.0 \%$ (inexperienced vs. experienced) to $44.1 \%$ (inexperienced vs. experienced) on day 2. Results for interrater reliability of first ray mobility are shown in Tables D8-D10. Frequencies for mobility results by examiner on day 1 and day 2 are displayed in Figures D3 and D4. 


\section{DISCUSSION}

The intent of this study was to determine the intra and interrater reliability for and between experienced and inexperienced examiners in the measurement of first ray position and mobility using Root's technique. The hypothesis of the study was to determine that experienced examiners would have moderate to high intra and interrater reliability for position while inexperienced examiners would have low to moderate intra and interrater reliability for position. Intrarater reliability results, however, indicated slight to fair agreement for experienced and poor to fair agreement for inexperienced examiners. The results indicated that experienced examiners had poor to slight agreement and inexperienced examiners had slight agreement for interrater reliability.

The hypothesis of the study for mobility measurements was also to determine that experienced examiners would have moderate to high intra and interrater reliability for position while inexperienced examiners would have low to moderate intra and interrater reliability. Intrarater reliability for experienced examiners was also low, having poor to slight agreement. Inexperienced examiners, though, had slight to fair agreement for intrarater reliability. Experienced and Inexperienced examiners had only slight agreement for interrater reliability.

There were few significant correlations indicated by this study. Intrarater reliability appeared to be slightly higher for position and mobility measurements. The most significant data were shown with I2, whom was thought to be the stronger of the inexperienced examiners. Intrarater reliability for position measurements for I2 and E1 and for mobility measurements for I1 and I2 were significant. Interrater reliability between 
I2 and each of the other three examiners had at least one significant result on day 2. I2 had the highest interrater reliability for position on both days with an experienced examiner.

The nature of kappa coefficients will cause two raters who have a high percent of agreement to have a low kappa coefficient, especially when there is an uneven balance in the different categories (hypermobile, hypermobile, and normal or plantarflexed, dorsiflexed, and normal). ${ }^{22,23,24}$ An example of this is that one examiner in this study had a tendency to choose normal for most of the subjects' position and mobility testing. Another examiner had a tendency to choose that more subjects had hypermobility or plantarflexion. Because none of the other examiners chose the same categories as often, an uneven distribution was created, causing a lower kappa coefficient.

Low $K / K m a x$ proportions indicated a large discrepancy between each examiner's decision and the best agreement that could occur without chance, therefore distributions contributed to lower kappa reliability. The highest $K / K \max$ was found for intrarater reliability for mobility at 50.6\% $(\mathrm{P} \leq 0.001)$. This was for the examiner who had a high tendency to choose normal. The remaining intra and interrater reliability kappa coefficients also reached a low percentage of the $K \max$. Therefore, uneven distributions were not the sole reason for the low kappa reliabilities.

Factors of Low Reliability

Suggested reasons for low reliability include inconsistency with the measurement technique, each examiner's decision rules, and true history of experience of the examiners. A standardized technique was shown and practiced prior to the first testing day. Each examiner was shown Root's method, how to interpret the subject's feet, and that the foot was to be in subtalar joint neutral during testing. Despite the emphasis during practice 
sessions, examiners were not always consistent with placing the subtalar joint in neutral during testing. This is a concern because when the foot is in subtalar joint neutral and the midtarsal joint maximally pronated, plantarflexion and dorsiflexion should be equal. ${ }^{7,9}$ Bevans $^{25}$ indicated that by allowing the foot to be measured with the calcaneus in eversion or inversion, which occurs when the foot is not in subtalar joint neutral, first ray dorsiflexion changes. When the calcaneus is in eversion, first ray dorsiflexion increases while when the calcaneus is in inversion, first ray dorsiflexion is decreased. This inconsistency was more commonly observed in inexperienced rather than experienced examiners. This may be an indication, though, of true measurement consistency in everyday practice.

All examiners also had a tendency to doubt their interpretations, feeling as if they may be occasionally reporting the wrong results. This may be due to inexperience with the technique and/or the lack of practice on the second day. All examiners were given ample time and opportunity to practice the technique prior to testing on the second day, but all felt comfortable from the previous week and declined practice opportunities. The low interrater reliabilities reported by Glasoe et al. ${ }^{19}$ may have been due to the lack of practice prior to testing. Placing a practice time half-way through the data collection each day may have alleviated any slighted rationales or psychophysical functions that may have caused the doubts. ${ }^{26}$ It is suggested that examiners may need a reminder of what each measurement feels like after performing a certain number of measurements. This may be why interrater reliability did not significantly increase on the second day.

Each examiner judges a biomechanical examination by personal decision rules ${ }^{23}$ of visual evaluation and feel of movement. An examiner's decision rules may allow the 
results of a biomechanical exam to be replicated by the examiner, which is why two different examiners have a lower chance of agreeing. The pressure placed when dorsiflexing and plantarflexing the first ray is often different for each individual. One examiner may not naturally put as much pressure into a measurement as another due to inexperience or weakness of the hand or grip strength. Several subjects supported this by indicating after their sessions that they noticed a stronger force when an experienced examiner performed the mobility test. Inexperienced examiners may have a fear of causing pain if too much pressure is exerted or may be unfamiliar with how much pressure is needed to obtain a true measurement. An inexperienced examiner may also not interpret the movement or visualize in which direction they are receiving more movement. Another problem that may occur is that rather than not exerting enough pressure, too much pressure may be exerted. ${ }^{19}$ A study utilizing a first ray mobility measuring device found that when $20 \mathrm{~N}, 35 \mathrm{~N}, 55 \mathrm{~N}$, and $85 \mathrm{~N}$ were separately applied, the application of $55 \mathrm{~N}$ of force obtained the best force with the least unwanted movement in the forefoot and rearfoot. ${ }^{4}$ Although this is a measurement taken with the device rather than manually, the validity of such a measurement depends on the force applied. In this study, force application was not measured.

The fat pad plantar to the first metatarsal may also be thicker on some subjects, regardless of the position or movement of their first ray. More experienced examiners might naturally factor that into an assessment. Experience may allow for differences in how much of a measurement is based on palpation compared to visual assessment. These appeared to be factors in this study. Results indicated that both experienced examiners on both days and both inexperienced examiners on day 2 had a higher tendency to choose 
plantarflexion over dorsiflexion (Figures D1 and D2). Both inexperienced examiners had a higher tendency to choose dorsiflexion over plantarflexion on day 1 . Similarly, one experienced examiner on day one and both experienced examiners on day two had a higher tendency to choose hypermobile over hypomobile while both inexperienced examiners had a higher tendency to choose hypomobile on both days (Figures D3 and D4).

Hand dominance and eye dominance may also have played a part in the examiner's decisions. A study by Dane et al. ${ }^{27}$ indicated that left handed examiners may focus both eyes to a closer distance than right handed examiners, giving left handed examiners an advantage on spatial and nonverbal perception. Since physical examinations involving manipulation do involve spatial perception, this may be a factor for the examiners. A right-hand dominant examiner may get better mobility results with a subject's right foot because on the subject's right foot, the right hand will be causing the excursion of the first ray while the left stabilizes. This should not have played a factor in this study, though, because all four examiners were right-handed. Similarly, eye dominance may affect an examiner's decision. An examiner who is primarily right eye dominant may have higher reliability with position and mobility on the right foot rather than the left foot. Dane et al. ${ }^{27}$ study indicated that there is no apparent discrete distribution with eye dominance. This was not determined in this study, therefore it cannot be determined if this was a factor.

A final factor influencing low reliability is the true experience that each examiner has with first ray measurement techniques. Both inexperienced examiners were second year graduate students and Root's technique of measuring first ray position and mobility was briefly practiced in a biomechanics course one year prior to this study. Both 
examiners worked as graduate assistants at a high school where there is limited time for biomechanical examinations. The fact that both inexperienced examiners had the most similar current history of first ray measurements may be the reason that the first ray measurements intra and interrater reliabilities averaged slightly higher than those of the experienced examiners. I2, though, had a stronger undergraduate background in foot and ankle biomechanical evaluations than I1, which may be why some of I2's results were more similar to experienced examiners.

Of the experienced examiners, E1 worked in a sports medicine clinic as a physical therapist and athletic trainer, while E2 worked at the college level in a busy athletic training room where biomechanical examinations were not common. It was unknown how many first ray measurements each examiner did on any given day. Although E2 had more than six years of experience as a certified athletic trainer, the incidence of first ray measurements may not be as common as E1 who worked in a sports medicine clinic. Neither experienced examiner, though, was familiar with Root's technique. These factors may be why I2 and E2 had the highest interrater reliability on both days for position testing and why the second inexperienced examiner had the most significant results of all examiners. This information indicates that experience alone does not result in higher reliability. A lack of a gold standard to confirm the actual position and/or mobility of the first ray leaves question to which examiner(s) obtained most valid results.

Clinical Implications

Clinical significance is the professional worth obtained from statistically significant data. ${ }^{28}$ Statistical significance must be obtained for correlation coefficients, but clinical significance is not always present when there is statistical significance. Although 
statistically significant correlations were obtained for both experienced and inexperienced examiners, there is little to no clinical significance indicated in this study. Using a large sample of subjects $(n=76)$ may be one reason that statistical significance was obtained. Larger samples sometimes allow for smaller effects to reach statistical significance when there is no real clinical significance. ${ }^{28}$ The precision of a statistic increases as the number of subjects increases. If a lower number of subjects had been used and the same results were obtained, there may not have been any statistically significant results. A larger sample theoretically should ensure normal distributions and be more representative of the population.

Statistical intra and interrater reliabilities of no to fair agreement ${ }^{24}$ indicate clinically that if two clinicians were to examine the same patient in the clinic, it is likely that they will not perceive the same results. Furthermore, these reliabilities also indicate that a clinician has a low chance of obtaining the same results on a patient on two different occasions, leaving one to question to whether treatments dependent upon the results are appropriate. Figures D1-D4 are indicators of how much variability each examiner had when compared to themselves and when compared to other examiners on the same measurements.

This study, however, did not follow the pattern that would typically be followed in a sports medicine setting. Typically, combined biomechanical measurements would be taken while objective and subjective information would be available to the clinician to help determine appropriate treatment modifications. For this study a standardized technique utilizing only one part of the biomechanical exam was necessary for research purposes. 
The examiners in this study did not perform as predicted based upon their level of clinical experience. In a typical sports medicine setting, though, clinicians do not have similar experiences. It is very common for clinicians fitting our definitions of inexperienced and experienced to work side by side. Therefore, the results of this study further indicate that if the examiners in this study cannot produce reliable results, then they may not be able to produce reliable results in the sports medicine setting. Since intrarater reliability was higher than interrater reliability in this study, the results further indicate the importance of consistency of clinicians for each patient. It is not uncommon, though, to have intrarater reliability because it is easier for one examiner to replicate their own results rather than another examiners' results.

Although Root's ${ }^{7,8}$ technique was used in this study, the consistently low reliability scores also leave questions as to the use and reliability of using this particular first ray measuring technique clinically. However, a study by Hamill et al. ${ }^{18}$ implies the importance of first ray measurements in relation to dynamic lower extremity measures. The study indicated that by using Root's first ray manual measuring technique, a high correlation was found between mobility and knee rotation $(\mathrm{r}=0.83)$ and anteroposterior ground reaction forces $(\mathrm{r}=0.78)$. This information leads us to believe that eliminating this measurement from a biomechanical examination may not be the right course of action. First ray position and mobility measurements are essential elements when determining treatment options for the lower extremity. ${ }^{29}$ Use of the first ray measuring device is not a feasible option for athletic training rooms and sports medicine clinics due to its lack of availability and probable cost. Therefore, measures need to be taken to increase the reliability of this test. This may be possible by making available more first ray 
measurement continuing education courses or by developing more stringent guidelines for testing to increase reliability. ${ }^{30}$

The results of this study support Glasoe et al.'s ${ }^{19}$ finding of slight agreement with interrater reliabilities for first ray manual measurements. When comparing a first ray mobility measuring device to a surgeon's manual measurements Glasoe et al. ${ }^{19}$ found a negative correlation ( $\mathrm{r}=-0.21)$, leaving question as to the validity of Glasoe's manual measuring technique. However, as indicated in a study by White et al. ${ }^{30}$, one needs to be careful when interpreting and comparing results from a study where the technique used was created by the author. Although it is the only other study that evaluates reliability of first ray measurements, Glasoe himself created the measurement technique used, therefore the examiners could have had a stronger theoretical basis for the measurement technique. Furthermore, the reliability determined for the measurement technique used by Glasoe et al. ${ }^{19}$ cannot be applied to Root's ${ }^{7,8}$ technique. ${ }^{29}$ While Root's first ray mobility technique relies on dorsal and plantar motion of the first ray, Glasoe's first ray mobility technique only requires the application of dorsal force in comparison to the lateral four metatarsals. The choice of using one method over another can affect the results of first ray mobility measurements. ${ }^{29}$ Glasoe's method may seem to be easier to use, but Root's technique is used more often in the clinical setting.

\section{CONCLUSION}

This study found that inexperienced examiners had poor to fair agreement while experienced examiners had slight to fair agreement for intrarater reliability of first ray position measurements. Experienced examiners had poor to slight agreement while inexperienced examiners had slight agreement for interrater reliability of first ray position 
measurements. Experienced examiners had poor to slight agreement for intrarater reliability and slight agreement for interrater agreement of first ray mobility measurements. Inexperienced examiners had slight to fair agreement for intrarater reliability and slight agreement for interrater agreement of first ray mobility measurements. Results from this study support that the same clinician should evaluate the same patient to decrease inconsistent measurements in the sports medicine setting. Although these measurements indicate low reliability in the present study, this measurement does have an affect on several dynamic lower extremity measures ${ }^{18}$ and it is still a measurement used to help sports medicine professionals evaluate and determine appropriate treatment interventions for the first ray. 


\section{REFERENCES}

1. Glasoe WM, Allen MK, Ludwig PM. Comparison of first ray dorsal mobility among different forefoot alignments. J Orthop Sports Phys Ther.

2000;30(10):612-23.

2. Glasoe WM, Allen MK, Yack HJ. Measurement of dorsal mobility in the first ray: elimination of fat pad compression as a variable. Foot Ankle Int. 1998;19(8):5426.

3. Glasoe WM, Yack HJ, Saltzman CL. Anatomy and biomechanics of the first ray. Phys Ther. 1999;79(9):854-9.

4. Glasoe WM, Yack J, Saltzman CL. Measuring first ray mobility with a new device. Arch Phys Med Rehabil. 1999;80:122-4.

5. Glasoe WM, Yack HJ, Saltzman CL. The reliability and validity of a first ray measurement device. Foot Ankle Int. 2000;21(3):240-5.

6. Johnson $\mathrm{CH}$, Christensen JC. Biomechanics of the first ray part I. The effects of peroneus longus function: A three-dimensional kinematic study on a cadaver model. J Foot Ankle Surg. 1999;38(5):313-321.

7. Root ML, Orien WP, Weed JH. Normal and Abnormal Function of the Foot: Clinical Biomechanics: Volume II. Clinical Biomechanics Corporation. Los Angeles, CA, 1977:p48-51, 265-6, 285, 344-5, 350-4, 358-9, 363-7, 376-7.

8. Root ML, Orien WP, Weed JH, Hughes RJ. Biomechanical Examination of the Foot. Clinical Biomechanics Corporation. Los Angeles, CA, 1971:p76-87.

9. Catanzariti AR, Bosta SD, Distazio J. Peroneus longus tendon lengthening. J Foot Surg. 1986;25(6):450-5.

10. D'Amico JC, Schuster RO. Motion of the first ray: clarification through investigation. J Am Pod Assoc. 1979;69(1):17-23.

11. Donatelli R, Wolf SL: The Biomechanics of the Foot and Ankle. F.A. Davis Company. Philadelphia, PA, 1990.

12. Fritz GR, Prieskorn D. First metatarsocuneiform motion: a radiographic and statistical analysis. Foot Ankle Int. 1995;16(3):117-123.

13. Bierman RA, Christensen JC, Johnson CH. Biomechanics of the first ray. Part III. Consequences of the Lapidus arthrodesis on peroneus longus function. A threedimensional kinematic study in a cadaver model. J Foot Ankle Surg. 2001;40(3):125-31. 
14. Glasoe WM, Allen MK, Saltzman CL. First ray dorsal mobility in relation to hallux valgus deformity and first intermetatarsal angle. Foot Ankle Int. 2001;22(2):98-101.

15. Lee KT, Young K. Measurement of the first-ray mobility in normal vs. hallux valgus patients. Foot Ankle Int. 2001;22(12):960-4.

16. Roling BA, Christensen JC, Johnson CH. Biomechanics of the first ray. Part IV: The effect of selected medial column arthrodeses. A three-dimensional kinematic analysis in a cadaver model. J Foot Ankle Surg. 2002;41(5):278-285.

17. Roukis TS, Scherer PR, Anderson CF. Position of the first ray and motion of the first metatarsophalangeal joint. J Am Pod Med Assoc. 1996;86(11):538-545.

18. Hamill J, Bates BT, Knutzen KM, Kirkpatrick GM. Relationship between selected static and dynamic lower extremity measures. Clin Biomech. 1989;4(4):217-225.

19. Glasoe WM, Allen MK, Saltzman CL, Ludewig PM, Sublett SH. Comparison of two methods used to assess first-ray mobility. Foot Ankle Int. 2002:23(3):248252 .

20. Voellmicke KV, Deland JT. Technique tip: Manual examination technique to assess dorsal instability of the first ray. Foot Ankle Int. 2002;23(11):1040-1.

21. Watson CJ, Propps M, Galt W, Redding A, Dobbs D. Reliability of McConnell's classification of patellar orientation in symptomatic and asymptomatic subjects. $J$ Orthop Sports Phys Ther. 1999;29(7):378-385.

22. Cohen JA. A coefficient of agreement for nominal scales. Educ Psychol Meas. 1960;20(1):37-46.

23. Hayes KW, Petersen CM. Reliability of classification derived from Cyriax's resisted testing in subjects with painful shoulders and knees. J Ortho Sports Phys Ther. 2003;33(5):235-245.

24. Landis JR, Koch GG. The measurement of observer agreement for categorical data. Biometrics. 1977;33:159-174

25. Bevans JS. The influence of subtalar joint position on first-ray dorsiflexion: A pilot study. B J Pod. 2003;6(3):69-72.

26. Sekizawa K, Sandrey MA, Ingersoll CK, Cordova ML. Effects of shoe sole thickness on joint position sense. Gait Post. 2001;13:221-228. 
27. Dane S, Gumustekin K. Correlation between hand a preference and distance of focusing point of two eyes in the horizontal plane. Int J Neurosci. 2002;112(10):1141-1147.

28. Kinzey SJ. Significance, statistical or practical-the question of so what [editorial]? J Sport Rehabil. 2000;9(4):267-8.

29. Nawoczenski DA, Baumhauer JF, Umberger BR. Relationship between clinical measurements and motion of the first metatarsophalangeal joint during gait. J Bone Joint Surg. 1999;81-A(3):370-375.

30. White LJ, Thomas JS. The rater reliability of assessments of symptom provocation in patients with low back pain. J Back Musculoskel Rehabil. 2002;16:83-90. 
APPENDICES 


\section{APPENDIX A}

\section{THE PROBLEM}

\section{Research Question}

Normal motion of the first ray joint has been found to be an essential element of the foot during the gait cycle. ${ }^{17,31,32}$ During the gait cycle, the first ray provides shock absorption during the loading response and stability in the terminal stance and pre-swing. Abnormal first ray mobility (hyper or hypomobility) or position (plantarflexion or dorsiflexion) decreases the ability of the first ray to carry out its normal function. Abnormal first ray mobility or position has been indicated to alter lower extremity biomechanics. ${ }^{1-3,5,7,13-18}$ However, there is little research on first ray measurements. First ray position and mobility are commonly assessed manually on patients during a biomechanical exam. ${ }^{3,19}$ Only one first ray position measurement technique exists while several manual first ray mobility measurement techniques exist. ${ }^{71}{ }^{19}$ Glasoe et al.' ${ }^{19}$ first ray mobility technique has been examined for reliability while no other studies exist regarding any other technique for measuring first ray mobility or position. In addition, the published intertester reliability measurements were poor. ${ }^{19}$ To validate the technique, Glasoe first developed a first ray mobility-measuring device and compared that with radiographs to obtain validity for the device. ${ }^{3,15,20}$ The validated first ray mobilitymeasuring device was then compared with the first ray mobility manual measurement to obtain validity while inexperienced and experienced examiners performed the first ray mobility manual measurement to obtain reliability. ${ }^{19}$ Since neither the first ray mobility measuring device nor radiographs are readily available or practical in the sports medicine setting, it is important to examine the first ray and its clinical evaluation techniques. 
Although Root's technique of measuring first ray position and mobility is used more often than Glasoe's in the sports medicine setting, there is no research examining Root's technique nor the effects of evaluator experience on reliability using Root's technique. It is of interest, then, how reliable this test may be when compared between examiners who have little experience and those who have six or more years of experience with lower extremity measurements. Two research questions will be explored using this study. Will experienced examiners have a higher reliability of manual testing than inexperienced examiners when using Root's technique of first ray position and mobility testing? How reliable is Root's technique of first ray position and mobility testing over time? Experimental Hypotheses

1. The interrater and intrarater reliability will be moderate to high for position in experienced examiners.

2. The interrater and intrarater reliability will be moderate to high for mobility in experienced examiners.

3. The interrater and intrarater reliability will be low to moderate for position in inexperienced examiners.

4. The interrater and intrarater reliability will be low to moderate for mobility in inexperienced examiners.

\section{Assumptions}

1. The examiners measured first ray mobility to the best of their ability and gave correct and accurate results to the best of their knowledge.

2. The inexperienced examiners were truly inexperienced in this technique. 
3. The experienced examiners were truly experienced in lower extremity evaluations.

4. Subjects completed the history questionnaire honestly and to the best of their ability.

Delimitations

1. Subjects used for examination had no exclusions due to abnormalities, although there was an exclusion for a history of foot surgery; therefore abnormalities may have influenced mobility of the first ray.

2. Only two inexperienced and two experienced examiners were used, therefore the results of this study may not have represented the entire population.

3. Only thirty-six subjects were used, therefore the results of this study may not have represented the entire population.

4. The manual method of measuring first ray mobility was standardized.

5. Subjects were recruited using a sample of convenience, therefore there was a lack of generalizability.

\section{Operational Definitions}

1. Center of rotation- Center of a fixed axis upon which an object rotates around. ${ }^{11}$

2. Clinical significance- It is the professional worth obtained from statistically significant data. ${ }^{28}$ Statistical significance must be obtained to find clinical significance, but clinical significance is not always found when there is statistical significance. This definition was used solely for the purpose of this study. 
3. Dorsiflexion- Dorsal movement of the first ray on the sagittal plane. ${ }^{11}$

4. Experienced- An experienced examiner was labeled for this study a certified athletic trainer or licensed physical therapist with six or more years of clinical experience in their field and an individual who works with athletes/patients having lower extremity pathology. They should have felt relatively comfortable with this task.

5. First ray- A single functioning unit consisting of the first metatarsal and medial cuneiform along with the connecting joint, ligaments, and capsule. ${ }^{1-6,10,12}$

6. First ray mobility- Range of motion of the first ray in the metatarsal and medial cuneiform along with the connecting joint, ligaments, and capsule sagittal plane of motion. $^{33}$

7. First ray mobility measuring device- Device created and improved over the years to measure the mobility of the first ray., ${ }^{2,33}$ This device is not widely available.

8. First ray position- How the first ray lies distally in comparison to the lateral four metatarsals when no pressure is being applied to the first ray and the foot is in subtalar joint neutral. ${ }^{11}$ It can be excessively long or short, in a dorsiflexed, or plantarflexed position. ${ }^{17}$

9. Forefoot varus- A frontal plane inversion deformity of the forefoot on the rearfoot. $^{11}$

10. Hallux limitus- First metatarsophalangeal joint deformity in which the proximal phalanx of the hallux is plantar in relation to the first metatarsal. ${ }^{7}$ 
11. Hallux rigidus- First metatarsophalangeal joint deformity in which degenerative changes such as ankylosis of the joint or osseous compression at the articular surfaces occurs. ${ }^{7}$

12. Hallux valgus (abductovalgus ${ }^{7}$ )- A soft tissue subluxing deformity of the first metatarsophalageal joint where the hallux abducts due to the inversion of the first metatarsal, which occurs due to hypermobility. ${ }^{7}$

13. Hypermobile (First ray insufficiency ${ }^{11}$ )- When the amount of dorsiflexion exceeds the amount of plantarflexion. ${ }^{8}$ Dorsal excursion of the first ray with a soft endpoint. ${ }^{6,16,35-37}$ Clinically this was detected during the manual test when the plantar fat pad elevates above the plantar level of the lateral four metatarsals., 39

14. Hypomobile (Stiff)- When the amount of plantarflexion exceeds the amount of dorsiflexion. ${ }^{8}$ A rigid deformity of the first ray, possibly caused by pathological changes in the tissues. ${ }^{11}$ Clinically this was detected during the manual test when the plantar fat pad cannot elevate to the plantar level of the lateral four metatarsals. $^{3,19}$

15. Inexperienced- An inexperienced examiner was labeled for this study as a certified athletic trainer or licensed physical therapist with less than two years of clinical experience in their field of study. They will be second year graduate athletic training students at West Virginia University and who had completed classes in anatomy and biomechanics, but they had little to no experience with this task and may not have felt completely comfortable with it. 
16. Manual techniques- Evaluation techniques using little to no equipment other than the examiner him/herself.

17. Normal- Clinically this was detected during the manual test when the plantar fat pad elevates to the plantar level of the lateral four metatarsals. ${ }^{3,19}$

18. Plantarflexion- Plantar movement of the first ray in the sagittal plane. ${ }^{11}$

19. Sagittal plane- Plane dividing the body into right and left halves and that allows movements of flexion and extension, which includes plantarflexion and dorsiflexion. ${ }^{11,38}$ Its axis is perpendicular to the plane of motion, crossing from left to right and parallel to the ground. ${ }^{11}$

20. Stance phase- Phase of the gait cycle where the foot is in contact with the ground. ${ }^{38}$ It lasts from heel strike to toe off and consists of $60 \%$ of the gait cycle.

21. Statistical significance- Occurs when the obtained value of a study exceeds the appropriate table significance, even if no practical significance is present. ${ }^{28}$

22. Subtalar joint neutral- When the calcaneus is perpendicular to the ground and parallel to the distal $1 / 3$ of the leg. ${ }^{7}$ The foot is nonweight-bearing and the foot is in neither pronation nor supination.

23. "Windlass" effect- As the first ray moves into dorsiflexion, the plantar pad and aponeurosis will move distally and shorten the distance between the hallux and the calcaneus, which will pull the medial arch taut, therefore stabilizing the arch and foot, causing the "windlass" effect. 1, 3, 17, 37, 39, 40 


\section{Limitations}

1. There is no "gold standard" to compare measurements to. Although results may be reliable, they may not be valid.

Significance of the Study

The clinical significance of this study was to learn how reliable Root's technique for position and mobility is and how accurate clinicians are when using this test. Athletic trainers and other clinicians widely use this clinical test to evaluate first ray mobility. The results found by clinicians determine the treatment that an athlete or patient may undergo. Studies indicate that Root's first ray mobility technique is highly correlated with knee rotation and anteroposterior ground reaction forces. Known reliability of Root's technique will allow athletic trainers and other clinicians to determine how effective this test may be for determining an athlete or patient's treatment. Using standardized manual techniques will test the true reliability of first ray clinical measurements between experienced and inexperienced examiners. It will also allow instructors to determine whether more experience and practice is needed during educational settings to increase the reliability of inexperienced examiners. A consistent low reliability of the manual technique may lead to the eventual elimination of first ray measurements in the clinical setting. By addressing this possibility with reliability studies, steps can be taken to increase first ray measurement reliability. 


\section{APPENDIX B \\ LITERATURE REVIEW}

Introduction

The first ray is made up of the first metatarsal, medial cuneiform, and their connecting ligaments, joint capsule, attached muscles, and the sesamoids. Ligaments, bones, and musculature are important for structural stability of the first ray. ${ }^{13}$ Stressrelated and chronic injuries may be related to problems with the first ray. Abnormal biomechanics of the first ray can lead to several problems, including metatarsalgia, metatarsal stress fractures, tibial stress fractures, hallux valgus (hallux abductovalgus ${ }^{7}$ ), posterior tibialis and peroneus muscle fatigue and dysfunction, acquired flatfoot deformity, and ulcerations of the plantar surface of the foot. ${ }^{1-3,5,7,13-17}$

Abnormal position of the first ray has also been found to alter the biomechanics of the first ray. ${ }^{17,37}$ This can be observed in patients with metatarsus primus elevatus, immobilization of the first ray, a short or long second metatarsal, or hypermobility of the first ray. ${ }^{17}$ It is believed that these abnormal positions of the first ray affect the performance of normal motion.

Normal motion of the first ray joint has been found to be very important during the gait cycle in the functioning of the foot, especially motion in the sagittal plane. ${ }^{17,31,32}$ Motion is commonly assessed manually during a biomechanical exam. ${ }^{3,19}$ Clinically, motion is measured by stabilizing the lateral four metatarsals with one hand and dorsally manipulating the first ray from the plantar surface with the opposite hand. 3, 4, 16, 19 The results are measured as hypermobile, hypomobile, or normal. ${ }^{3,19}$ In this review of the 
literature, information on anatomy, biomechanics, epidemiology and etiology, evaluation, and treatment of the first ray have been included.

\section{Anatomy}

The first ray is a single functioning unit consisting of the first metatarsal and the $1^{\text {st }}$ (internal) cuneiform (Figure B1). ${ }^{1-12}$

\section{C) Second Metatarsal}

Figure B1. Dorsal view of the foot ${ }^{10}$

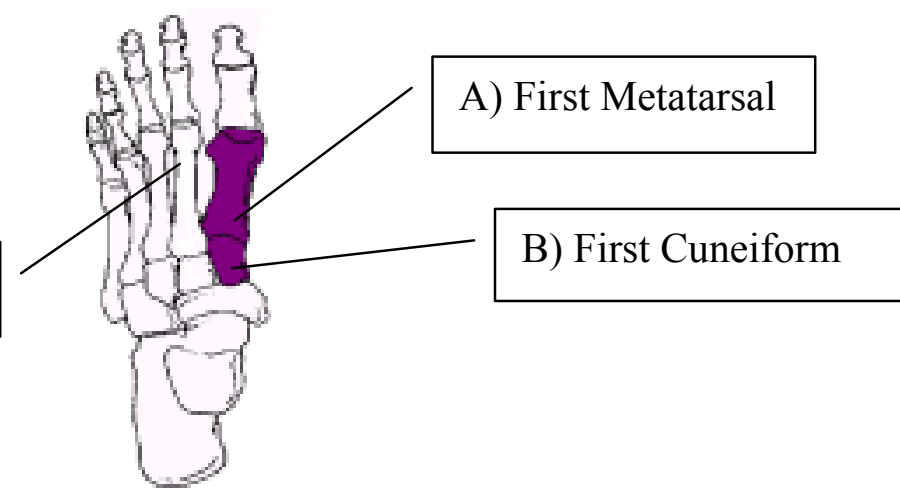

The first metatarsal is naturally shorter in length, but twice the width as the second metatarsal and has been found to have four times the strength. ${ }^{3,11,41,42}$ It is formed by a base, head, and a shaft. ${ }^{41}$ It has a large quadrilateral joint surface at the head of the metatarsal, minimizing joint forces. ${ }^{11,41,42}$ The articular surface on the long axis of the bone is flat and oriented laterally and downward. ${ }^{41}$ Three surfaces included in the shaft of the first metatarsal are the dorsomedial, lateral, and inferior surfaces. The base of the first metatarsal is concave and triangular with articulating surfaces to the cuneiform on its lateral, medial, and inferior surfaces. ${ }^{41,43}$ Radiographs distinguish the three possible types of articular facets between the base of the first ray and the second metatarsal. ${ }^{12,15,44}$ They include type I, having no articular facet, type II, having a transitional articular facet, and

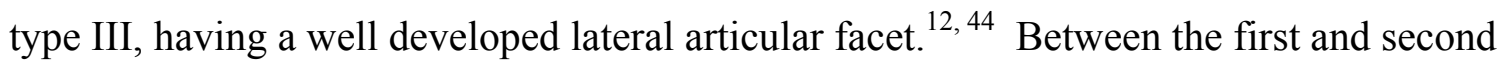


metatarsal, there is a $3-9^{\circ}$ intermetatarsal angle formed in most adults and $2-8^{\circ}$ angle in adolescents. ${ }^{41}$

The first cuneiform has a total of five surfaces, not including the crest. ${ }^{41}$ These include the anterior, posterior, lateral, inferior, and medial surfaces. Articulation with the base of the first metatarsal occurs on the convex anterior surface. ${ }^{41,43}$ The posterior surface of the cuneiform articulates with the navicular and the lateral surface articulates with the second cuneiform. ${ }^{41}$ The inferior and medial surfaces allow for muscle and ligamentous attachments. Three variable slopes have been found in the distal first cuneiform that can be seen on dorsoplantar radiographs. ${ }^{12}$ They include class I, which is a relatively transverse slope $<10^{\circ}$, class II, which has an intermediate slope of $10-20^{\circ}$, and class III, which has a slope $>20^{\circ}$. Lateral radiographs distinguish the three distinct shapes of the cuneiform, including S-shaped, linear, and convex.

There are broad ligaments attaching the first metatarsal and medial cuneiform, allowing little to no separate movement. ${ }^{5,10,12}$ While weightbearing, the plantar first metatarsocuneiform ligament is a strong dense rectangular ligament stabilizing the first metatarsal. ${ }^{6,13,16,41}$ Instability and an average dorsal displacement of $5.9 \mathrm{~mm}$ has been found when this ligament is sectioned. ${ }^{16}$ The short and long plantar ligaments and the spring ligament also play a part in stabilizing the static structures of the foot. ${ }^{37}$ Cutting these plantar ligaments can result in up to $5 \mathrm{~mm}$ translation between the first metatarsal and the first cuneiform. The Lisfranc ligament connects the first ray and the second metatarsal by connecting the first cuneiform to the second metatarsal. ${ }^{3}$ The plantar aponeurosis and the transverse metatarsal ligaments also support and connect the metatarsals. ${ }^{3,13,37}$ The plantar aponeurosis stretches from the calcaneus to the proximal phalanx of the hallux, 
attaching by oblique fibers. ${ }^{17,37,41}$ It responds as a ligament to mechanical loads, as elastic to low loads, and with resistance to deformation to high loads. ${ }^{37}$

Beneath the head of the first ray lies a plantar fat pad that absorbs shock. ${ }^{2}$ It is filled with microchambers of fat that are separated by bands of collagen. Two sesamoid bones lie beneath the first metatarsal head, encased in the muscle belly of the flexor hallucis brevis, with possible functions related to the movement and abilities of the first ray. $^{3,45}$ These functions include elevation of the first ray to; a) allow plantarflexion of the metatarsal during extension of the first toe, $b$ ) increase the load bearing capacity of the first ray, and c) add additional mechanical leverage of muscles attaching to the first metatarsal. ${ }^{3}$ Because of numerous ossification centers in the sesamoid bones, they may be bi-, tri-, or even quadripartite in adults. ${ }^{45}$ Their average range of motion from full plantarflexion to dorsiflexion is $71.9^{\circ}$.

The peroneus longus, posterior tibialis, and anterior tibialis tendons insert on the first metatarsal. ${ }^{1,3,11}$ The peroneus longus attaches to the plantar lateral base of the first metatarsal and also to the lateral plantar aspect of the first cuneiform. ${ }^{6}$ The tibialis anterior inserts on the inferomedial aspect of the base of the first metatarsal and on the medial side of the first cuneiform. ${ }^{41}$ The tibialis posterior attaches fibers at the navicular and the inferior surface of the first cuneiform.

Arterial supply is from the first dorsal metatarsal artery and the first plantar metatarsal artery and their branches off of the dorsalis pedis artery. Plantar and dorsal veins arising from the first cuneometatarsal and interosseum and intermetatarsal joints drain into the greater saphenous vein. Cutaneous and muscular nerve supply arises from the medial plantar nerve, saphenous nerve, and the superficial and deep fibular nerves. ${ }^{38,41}$ 


\section{Biomechanics of the First Ray}

First ray motion occurs "at the first metatarsal-medial cuneiform joint, the medial cuneiform-intermediate cuneiform joint, and the medial cuneonavicular joint." ${ }^{\text {"17 }}$ The joints move together in unison along a common axis. ${ }^{8,17}$ The first ray functions on this independent axis that allows triplanar motion, $3,10,37$ and "angles approximately $45^{\circ}$ with the frontal and sagittal planes and slightly from the transverse plane." ${ }^{\prime 8,9,17,31}$ Motion in the closed kinetic chain results in more transverse plane motion and less sagittal motion. ${ }^{17}$ The axis runs from posterior, medial, and dorsal to anterior, lateral, and plantar. ${ }^{8-10}$ Because of this, movements of the first ray occur in either dorsiflexion, inversion, and adduction or plantarflexion, eversion, and abduction. ${ }^{8,9,16,17,31,46}$ Inversion occurs proportionately to the amount of dorsiflexion that occurs. ${ }^{17}$ This indicates that a first ray in excessive dorsiflexion will also invert to a greater degree. Other authors ${ }^{10,31}$ have disagreed, stating that plantarflexion occurs with inversion while dorsiflexion occurs with eversion. As the first ray moves in one direction, the fifth ray moves in the opposite direction. ${ }^{46}$ As the first ray moves in an extreme direction, the second ray moves in that direction only moderately and so on. Hicks et al. ${ }^{46}$ describes the forefoot as a constantly changing shape where there is no true axis. However, the unmoving third ray that sits in a transverse direction becomes the axis in most cases. There is little abduction or adduction movement of the first ray. ${ }^{9}$

The center of rotation for the first ray occurs between the naviculocuneiform joint and the metatarsocuneiform joint. ${ }^{15,16,34}$ The axis of rotation occurs at an oblique angle from the dorsolateral axis to the plantarmedial axis at $6.2^{\circ} .{ }^{15}$ Controversy exists on whether the instant center of rotation at the head of the first metatarsal occurs in the open 
kinetic chain from distal-dorsal to proximal-plantar or from proximal-plantar to distaldorsal. ${ }^{17}$ During closed kinetic chain rotation it has been found that the center of rotation occurs from distal-plantar to proximal-dorsal.

Sufficient force from the peroneus longus results in eversion and slight plantarflexion of the first metatarsal and the first cuneiform. ${ }^{6}$ The first ray is utilized as both a shock absorber and a stabilizer of the foot. ${ }^{2}$ Kelso et al. ${ }^{31}$ reported that the average range of motion of the first ray in the sagittal plane was $12.38 \mathrm{~mm}$ and the total motion in the frontal plane was $8.23^{\circ}$. A later study by Hamill et al. ${ }^{18}$ reported a mean range of motion of the first ray to be $16.9^{\circ}$. Minimal rotational movement in the first ray results in an average of $3.5^{\circ}$ of sagittal plane motion. ${ }^{47}$ Range of motion in the transverse plane ranges from $8^{\circ}$ to $10^{\circ}$. Previous studies have found that the average dorsal mobility in a healthy foot is $6 \mathrm{~mm}^{2,3}$, or about $5 \mathrm{~mm}$ above and $5 \mathrm{~mm}$ below the lateral four metatarsals. ${ }^{6}$,

${ }^{9}$ When the ankle is in subtalar joint neutral and the foot is maximally pronated, plantarflexion and dorsiflexion motion are equal. ${ }^{7,9}$

Within the tarsometatarsal joint, primary adduction and abduction are not commonly seen.$^{48}$ Dorsal displacement of the first metatarsal from the first cuneiform is possible, while plantar displacement has yet to be reported. Plantar displacement appears to be impossible because of the tendon attachments to the plantar and lateral surfaces and the tight joint capsule. After dorsal displacement occurs, a small amount of inversion and eversion is possible $\left(4.1^{\circ}\right.$ and $6.2^{\circ}$, respectively). Rotation in this joint can only occur if there is laxity and degeneration of ligaments. There is $3.5^{\circ}$ of flexion-extension motion and $1.5^{\circ}$ of pronation-supination motion at the first tarsometatarsal joint. ${ }^{49} \mathrm{~A}$ range of 
motion of $22^{\circ}$ occurs as the first metatarsal moves from flexion and pronation to extension and supination. ${ }^{41,46,49}$

There is a significantly different representation of the range of motion between the talonavicular joint and the metatarsocuneiform and naviculocuneiform joints. The medial naviculocuneiform joint averages $50 \%$ of the total motion of the first ray. ${ }^{16}$ The metatarsocuneiform joint averages $41 \%$ of first ray range of motion while the talonavicular joint only averages $9 \%$ of total first ray range of motion. There is $5^{\circ}$ of plantarflexion and dorsiflexion and $7.3^{\circ}$ of pronation and supination in the medial naviculocuneiform joint. ${ }^{49}$

In the normal foot, when the subtalar joint moves into pronation, the tibia internally rotates, causing the talus to adduct, plantarflex, and move anteriorly, which in turn changes the position of the navicular, affecting the cuneiforms and their adjacent metatarsals. ${ }^{10}$ The first ray is a dynamic stabilizer, therefore it does not carry much of the pressure placed on the forefoot while standing, although it does carry twice as much weight as the lateral four metatarsal bones. ${ }^{11,50}$ While walking, though, the first ray absorbs the most forces in the forefoot. Since an EMG did not indicate activity from the tibialis anterior, posterior tibialis, and peroneus longus while standing ${ }^{6}$, intrinsic ligaments must contribute to stability of the first ray. ${ }^{13}$ These muscles are, however, active during ambulation and important in the stability of the medial longitudinal arch. ${ }^{6}$ It is important for the first ray to have stability because it allows the medial arch to carry weight. ${ }^{19}$

First ray's role in gait: At the beginning of the stance phase, the subtalar joint is in pronation, placing the first ray closer to the ground. ${ }^{3}$ The first ray is unstable during this time, allowing the first ray to be used to dissipate shock at heel strike by dorsiflexing and inverting. ${ }^{3,7}$ During the gait cycle, the first ray is in an everted position. ${ }^{10}$ In midstance, 
the subtalar joint is in supination, placing the first ray higher than the cuboid. ${ }^{7}$ This lasts until the heel-off phase of the gait cycle begins. ${ }^{10}$ In these final stages of the stance phase, the forefoot bears about $40 \%$ of the body's weight, with the first ray taking the greatest amount. $^{42}$ As the foot prepares for heel-off, the subtalar joint continues in supination. ${ }^{7,11,}$ 39 The abductor hallucis and ground forces cause the first ray to plantarflex so that it stays in contact with the ground. ${ }^{7}$ This occurs as the first metatarsal head moves posteriorly, causing the sesamoids to move more distally under the first metatarsal head. ${ }^{7}$ The movement of the sesamoids allows the head of the first metatarsal to move below the lateral four metatarsals on the transverse plane, enabling full range of motion in the first metatarsophalangeal joint during heel-off. Maximum stability for push off is established by the "windlass" effect and supination. ${ }^{32}$ The peroneus longus muscle shows a large amount of electromyographic activity as it is concentrically activated to evert, stabilize, and plantarflex the first ray. ${ }^{1,9,11}$ It functions to stabilize the first ray against vertical ground forces. $^{7,9}$ It is assisted by a cuboid pulley., ${ }^{3,11}$ This burst of activity is most commonly seen during midstance and heel-off. ${ }^{6}$ To be an effective pulley system, the cuboid changes the direction of the pull of the peroneus longus. ${ }^{9,11,40}$ During the early propulsion phase of the gait cycle, the peroneus brevis muscle acts as an antagonist to the supinating muscles while the abductor hallucis muscle assists in plantar flexing the first ray. ${ }^{11}$ Strong electromyographic activity can be seen by the tibialis anterior during the swing phase to keep the toe from dragging on the ground. ${ }^{39}$

The first ray plays an important part in stabilizing the medial arch by the "windlass" effect." 13, 19,40 As the body moves forward in the stance phase, the weight shifts to the medial side of the forefoot and first metatarsal before the heel lifts. ${ }^{3,40}$ After 
the heel lifts, the ankle joint plantarflexes, causing the first ray and metatarsophalageal joints to dorsiflex. ${ }^{39}$ Anormal first ray will move within a normal range of motion as the plantar pad and aponeurosis will move distally and shorten the distance between the hallux and the calcaneus. ${ }^{3,17,37,39,40}$ This will pull the medial arch taut, therefore stabilizing the arch and foot, causing the "windlass" effect. Rush et al. ${ }^{37}$ observed that the biomechanical advantage of the "windlass" effect is optimal when abnormalities such as hallux valgus or metatarsus primus varus are not present and the first ray is in correct alignment.

Abnormal biomechanics: Abnormalities of first ray motion include hypermobility and hypomobility. Hypermobility has been described by Morton ${ }^{6,35}$ and Glasoe et al. ${ }^{36}$ as increased "dorsal excursion of the first metatarsal" with a soft end point. ${ }^{16,37}$ It displays an increased arc of motion. ${ }^{20}$ Morton $^{35}$ also described hypermobility as an "unusual spacing or degree of separation between the inner and middle cuneiform bones." Lee et al. ${ }^{15}$ described hypermobility to be $14^{\circ}$ or more or separation. The laxity occurs on the horizontal and sagittal planes. ${ }^{47}$ Myerson ${ }^{47}$ described hypermobility as motion greater than $8^{\circ}$ in the sagittal plane and $4^{\circ}$ in the horizontal plane. It is also defined as excessive motion by a full thumb breadth of dorsal motion and a dorsal displacement greater than $8-10 \mathrm{~mm} .^{20}$ A hypermobile first ray will have laxity in its plantar ligaments while the plantar ligaments attached to the second metatarsal will be taut. ${ }^{35}$ Laxity in the ligamentous structures eventually causes degeneration of the ligaments. ${ }^{47}$ Degeneration results in dorsal displacement of the first ray. During the gait cycle, a hypermobile first ray will shift dorsally, diverge medially, and rotate, not taking up the pressure that is required of it. ${ }^{3,14}$, 35, 36 This causes a dynamic shift in pressure to the $2^{\text {nd }}$ and $3^{\text {rd }}$ metatarsals and/or a compensatory mechanism of the first toe..$^{3,14,36}$ Since these metatarsals are not intended to 
be used during a great deal of the gait cycle, there is an increased risk of a $2^{\text {nd }}$ or $3^{\text {rd }}$ metatarsal instability or a stress fracture..$^{5,36}$

Pronation is a compensatory mechanism that has been found to be correlated with hypermobility. ${ }^{35}$ The first ray is an integral part of the longitudinal arch and laxity in the plantar ligaments decreases the effectiveness of the arch. To take up the slack in these ligaments, the foot must roll into pronation, decreasing the integrity of the foot's balance and decreasing the ability of the peroneus longus to stabilize the first ray against vertical ground forces. ${ }^{7,35}$ Fatigue in supinator muscles often occurs as a result of first ray hypermobility and decreased stabilization by the peroneus longus muscle, requiring the supinator muscles to work harder to compensate for the lack of bony integrity of the arch. ${ }^{35}$ The extent that pronation affects first ray hypermobility depends upon the amount of subtalar pronation that is present and the amount of calcaneal eversion that is present along with pronation. ${ }^{7}$ A greater amount of subtalar pronation will result in greater amount of first ray hypermobility. An everted calcaneus also decreases the plantarflexing force that is produced by the peroneus longus muscle. A pilot study by Bevans ${ }^{25}$ indicated that when the subtalar joint is in eversion, there is a mean of $12.4 \mathrm{~mm}$ of dorsiflexion while when the subtalar joint is in inversion, there is only a mean of $7.9 \mathrm{~mm}$ of dorsiflexion. To further enforce the effects that a hypermobile first ray affects the biomechanical chain, a study by Hamill et al. ${ }^{18}$ reported that increased laxity in the first ray increased the internal rotation and decreased the external rotation of the tibia $(R=0.94)$.

Compensation by the first toe to realign itself with the misaligned hypermobile toe can result in hallux valgus. ${ }^{5,14}$ Glasoe et al. ${ }^{14}$ observed a significant relationship between hallux valgus and dorsal mobility indicating that most patients with hallux valgus had an 
increased amount of dorsal mobility. Using radiographs to determine angles of the first ray and hallux, Lee et al. ${ }^{15}$ reported a low correlation $(\mathrm{r}=0.216)$ between hallux valgus angle and first ray range of motion. Patients with hallux valgus were found to have a $9.3 \mathrm{~mm}$ dorsiflexion in their first ray in comparison to the normal 5-6mm. ${ }^{6,34}$ Lee et al. ${ }^{15}$ observed an average first ray range of motion to be $10.3^{\circ}$ in normal patients and $12.9^{\circ}$ in hallux valgus patients. Metatarsalgia will result from hypermobility if enough irritation occurs under the second metatarsal and medial plantar nerve and its branches. ${ }^{7,35}$ Hypermobility of the first ray will decrease the effectiveness of the "windlass" effect which in turn will increase hypermobility. ${ }^{3,16}$ Rush et al. ${ }^{37}$ indicated that a first ray with normal sagittal plane motion at the metatarsal head, base of the metatarsal, and at the cuneiform had a significant increase in plantarflexion during the "windlass" effect in comparison to a first ray with abnormal motion.

A hypomobile, or stiff, first ray is a rigid deformity that will not allow the first ray to dissipate ground reaction forces at the beginning of the stance phase., ${ }^{3,11}$ It will often cause an increase in pressure under the first ray, leading to ulcerations in patients with insensitivity. ${ }^{3,15}$ Dynamic effects of a hypomobile first ray were indicated in a study by Hamill et al. ${ }^{18}$ These effects include a large affect on the anteroposterior component of ground reaction forces $(R=0.99)$ and a suppression of internal rotation and an increase in external rotation of the tibia. Congenital abnormalities related to a hypomobile first ray include metatarsus varus, where the tarsometatarsal joints are medially subluxed. ${ }^{11}$

Abnormal position of the first ray can also cause abnormal biomechanics. ${ }^{3}$ Abnormal position includes a dorsiflexed or a plantarflexed first ray. ${ }^{7}$ The abnormality can be congenital or acquired. ${ }^{7,9}$ A congenital deformity will have a bilateral abnormal 
position and full range of motion while an acquired deformity will have an abnormal position and restricted range of motion often unilaterally. An acquired and congenital plantarflexed first ray will be fixed into a plantarflexed position, but an acquired first ray will also have limited dorsiflexion during the non-weightbearing evaluation., 7-9, 11 Because of ligamentous attachments between the first and second metatarsals, the second metatarsal will also be plantarflexed, but not to the same extent as the first. ${ }^{11} \mathrm{~A}$ plantarflexed first ray will cause the foot to supinate throughout most of the gait cycle, causing the tibia to have limited internal rotation in early stance, decreasing shock absorption and ankle stability. ${ }^{3,7,11}$ As the rearfoot inverts along with a supinated subtalar joint, the peroneus longus will gain a greater mechanical advantage, plantarflexing the first ray even more. ${ }^{7}$ This will result in more supination in the subtalar joint, eventually ending with a pes cavus deformity of the foot.

A dorsiflexed first ray, or metatarsus primus elevatus, will have an abnormal dorsiflexed position in relation to the lateral four metatarsals. ${ }^{7,8}$ This deformity can affect the ability of the metatarsophalangeal joint to dorsiflex. ${ }^{7,8,17}$ It has been found that a dorsiflexed first ray has significantly decreased metatarsophalangeal joint motion from the weightbearing resting position by $19.3 \%$ for $4 \mathrm{~mm}$ dorsiflexion and $34.7 \%$ for $8 \mathrm{~mm}$ dorsiflexion. ${ }^{17}$ This is said to be the cause of hallux valgus, hallux limitus, and hallux rigidus.

Forefoot alignment has a good predictor significance for first ray mobility and the two have a moderate correlation $(\mathrm{r}=0.55) .{ }^{1}$ First ray abnormality may account for $30 \%$ of the dorsal mobility variablility. In patients with forefoot valgus, the midtarsal joint is in pronation during the late stance portion of the gait cycle because of an increased plantar 
force moment arm of the peroneus longus. ${ }^{1,3}$ This also places the first ray in a pronated position, decreasing the mechanical advantage of the peroneus longus. ${ }^{1,3}$ This causes stretching of the capsule and ligaments, resulting in instability and dorsiflexion. ${ }^{1}$ Forefoot supination often results in a failure of support in the first ray. ${ }^{50}$

Other factors related to the first ray can cause abnormal biomechanics. A first metatarsal that is too short and/or sesamoids lying too far posterior may allow the second metatarsal to take up extra stress by becoming the fulcrum in the foot's leverage during the gait cycle. $^{35}$ This may lead to hypertrophy of the second metatarsal, which is indicated with an increased size in the shaft. ${ }^{16,35}$ It is reported that an increased size in the shaft of the second metatarsal, or medial cortical thickening, has little correlation with range of motion $(\mathrm{r}=0.07) .^{32}$ A second metatarsal that is too short will not allow enough room for the first metatarsal to slide posteriorly during the propulsive phase of the gait cycle. ${ }^{7} \mathrm{~A}$ low correlation between the intermetatarsal angle and range of motion was found $(\mathrm{r}=0.2) .{ }^{32}$ A moderate correlation has been found for intermetatarsal angle $(\mathrm{r}=0.7)$ and hallux valgus $(\mathrm{r}=0.4)$ with toe pronation. ${ }^{51}$ A moderate correlation has also been found between intermetatarsal angle and sagittal plane mobility of the first ray $(\mathrm{r}=0.51) .{ }^{14}$ Structural malalignment of the sesamoids, such as fractured, subluxing, or dislocated sesamoids, has been correlated with degenerative pathologies occurring between the first metatarsal and the sesamoids. ${ }^{45}$ Bunions are highly correlated with hallux valgus and metatarsus primus varus. $^{52}$

Epidemiology and Etiology

Although the numbers are not available, diabetic patients who have a history of ulcerations on the plantar surface of their first metatarsal head will often have a plantar- 
flexed first ray. ${ }^{33}$ Lee et al. ${ }^{15}$ reported that $38 \%$ of hallux valgus patients had a hypermobile first ray. Four percent of the world has been found to have this deformity, regardless of the presence or type of footwear. ${ }^{47}$ Acquired hallux valgus is most commonly found in women and can often be a result of wearing narrow shoes with a narrow pointed toe box over a long period of time. ${ }^{11}$

Possible etiologic factors that may contribute to abnormal biomechanics in the first ray include osteoarthritis, avascular necrosis, arthritis, heredity, osteochondritis dessicans, neuromuscular disorders/imbalance, congenital disorders, abnormal range of motion, or acute trauma. ${ }^{17,50}$ Factors related to the position of the first ray such as metatarsus primus elevatus, abnormal length of the second metatarsal, and immobilization or hypermobility of the first ray may also contribute to abnormal biomechanics. ${ }^{17}$

Plantar foot ulceration plagues patients with diabetes mellitus due to problems with neuropathy, vascular problems, increased plantar pressure, and mechanical stresses. ${ }^{3,33}$ Many of these patients having foot ulcerations usually have decreased range of motion at the subtalar and ankle joints. ${ }^{33}$ If their first ray was plantarflexed, there was a greater chance of ulcerations under the first metatarsal head. ${ }^{3,33}$ A linear regression between first ray dorsiflexion and first metatarsal head pressure was significant $\left(\mathrm{R}^{2}=0.46\right)$, indicating that first ray range of motion is a significant predictor of peak pressure under the first metatarsal head. ${ }^{33}$

A shorter first metatarsal than the second metatarsal may be a cause of hypermobility of the first ray. ${ }^{35,36}$ If the first ray is shorter, the range of motion needed will be increased during push off of the gait cycle. Over time, this may lead to laxity in the 
first ray, causing hypermobility. Glasoe et al. ${ }^{36}$ observed metatarsal length to be a good predictor of first ray dorsal mobility.

General joint laxity may also be a cause of first ray hypermobility. This is indicated in patients with laxity in several joints in the body, or multijoint laxity. ${ }^{36}$ Glasoe et al. ${ }^{36}$ observed that general joint laxity was a good predictor for first ray dorsal mobility. Navicular drop, being an indicator of pronation, was not indicated as a good predictor of first ray dorsal mobility. Due to the laxity resulting from severe disorders such as Marfan syndrome and Ehlers-Danlos, there is a high risk of hypermobility of the first ray. ${ }^{47}$

The relationship between hallux valgus and hypermobility of the first ray is still uncertain. ${ }^{6}$ Uncertainty arises as to the cause of the deformity. Some believe that it begins proximal to the first ray while others believe it is due to hypermobility of the first ray. Ethnicity may affect the chance of a hallux valgus deformity. ${ }^{34}$ Hallux valgus is much more commonly found without symptoms in native americans than in caucasians. The type of shoewear is a common extrinsic factor that has been known to cause the hallux valgus deformity. ${ }^{47}$ Other factors include heredity, gender, pronation, long first ray, excessively rounded first metatarsal head, pronation of the foot or first metatarsal, neurological imbalance, and rheumatoid arthritis. ${ }^{52}$

A correlation between first and second metatarsal angles $\exists 10^{\circ}$ and medial arch angles $\exists 130^{\circ}$ has been found in patients with rheumatoid arthritis. ${ }^{53}$ This indicates that a weak adducting first metatarsal (metatarsus primus adductus), having an increased intermetatarsal angle, has a correlation with flat foot deformity and causes the ligamentous support between the two metatarsals to weaken. The subtalar joint laxity causes the 
posterior tibial tendon to stretch, therefore allowing the flat foot deformity to occur.

Laxity in the subtalar joint is caused by degeneration resulting from rheumatoid arthritis.

Evaluation

The evaluation begins with history and observation. A burning sensation under the sole of the foot may be indicative of metatarsalgia and/or a shift in pressure to the second metatarsal. ${ }^{35}$ If a patient has a hypermobile first ray, there will usually be calluses formed under the $2^{\text {nd }}$ and $3^{\text {rd }}$ metatarsals because of the shift in pressure to that area. ${ }^{16,32,35,36,47} \mathrm{~A}$ bunion deformity may be present on the lateral or dorsal side of the great toe in the case of a hypermobile first ray and/or hallux valgus. ${ }^{11,34,47}$ Individuals with hallux valgus may present with a hammertoe deformity, pain under the $2^{\text {nd }}$ and $3^{\text {rd }}$ metatarsals, and/or tenderness upon plantar palpation of the second metatarsal. ${ }^{34}$ Calluses may be present under the first and fifth metatarsals in the case of a plantarflexed first ray. ${ }^{3,9}$ These result from the increased pressure under the first ray and the compensating supination. Other symptoms of a plantarflexed first ray include a tender first metatarsal callus and a painful and fatigued medial arch.

Movement of the first ray is most commonly tested in the sagittal plane. ${ }^{33}$ Dorsal mobility is measured because during the gait cycle ground reaction forces force the first ray into the dorsal direction. ${ }^{3}$ It can be tested using radiographs, a first mobility measuring device, or manually, which is the most common of the three methods. ${ }^{3,15,19}$ Mobility measuring devices are very reliable, but are not practical nor widely available. ${ }^{20}$ Although reliability and validity first ray manual measurements are questionable using manual techniques $^{3,4}$, they are used most often and are more accessible. ${ }^{3}$ 
Manual techniques: The first ray is evaluated in the open kinetic chain by first placing the ankle and subtalar joints in neutral. $8,9,16,20$ The examiner then stabilizes metatarsals 2-5 with one hand and uses the opposite hand to apply dorsal force to the first ray from the plantar side. ${ }^{3,4,8,9,16,19}$ Mobility is then defined as normal, stiff, or hypermobile by evaluating the level the first metatarsal reaches during manipulation. ${ }^{3,19}$ Normal movement will be considered if the inferior portion of the metatarsal-sesamoid complex of the first ray can only be dorsiflexed to the same level as the other four metatarsals. The first ray is considered stiff if the complex cannot be dorsiflexed to reach the same level and it is considered hypermobile if the complex can be dorsiflexed past the other four metatarsals. Glasoe et al.'s ${ }^{19}$ study found that this method of evaluation has been reported to have poor interrater reliability $(\mathrm{K} \# 0.16)$ and high overall intrarater reliability $(0.73) .{ }^{19}$

Root et al.'s ${ }^{8}$ technique is similar to Glasoe et al.' ${ }^{19}$, but plantarflexing and dorsiflexing forces are applied in Root's technique whereas only dorsal forces are applied in Glasoe's technique. Normal movement is defined when the amount of plantarflexion is equal to the amount of dorsiflexion. ${ }^{8}$ Hypomobility is defined when the amount of plantarflexion exceeds the amount of dorsiflexion. Hypermobility is defined when the amount of dorsiflexion exceeds the amount of plantarflexion.

Voellmicke et al. ${ }^{20}$ describes the same method of measurement as Glasoe, except with the thumbs' interphalangeal joint bent at $90^{\circ}$ and using the tips of the thumbs to manipulate the first ray from the plantar surface. The measurement takes place at the dorsal surfaces of the proximal phalanges of the thumbs. Lee et al. ${ }^{15}$ describes a similar method completed by lying the thumbs flat against the plantar surface of the metatarsals 
and measuring from the fingernails. This method uses uses a right angled measuring device held at the head of the first metatarsal to measure movement and a right angled indicator to stabilize the lateral four metatarsals. A trigonomic formula is then used to translate the measurement from millimeters into degrees. A measurement of $14^{\circ}$ or higher is considered to be hypermobile. No reliability or validity has been reported regarding this method. Speculated reasons for such poor reliability were the examiner's inability to control the direction and dorsal pressure that is applied. ${ }^{19}$ Inter and intra-measurement differences may be minimized by performing multiple measurements. ${ }^{15}$ Small degrees of hypermobility are hard to ascertain by manual techniques. ${ }^{16}$

A second test that can be performed clinically to evaluate hypermobility of the first ray is the clinical squeeze test. ${ }^{47}$ During this test the forefoot and midfoot are grasped by the examiner between their thumb and index fingers. A hypermobile first ray is suspected if the first ray elevates dorsally.

Radiographs: Mobility of the first ray has been measured in the past by using radiographs. ${ }^{4,5}$ A lateral $\mathrm{x}$-ray is taken with the patient standing with the first ray propped and then unsupported by a $1.5 \mathrm{in}$. modified Coleman block to show the movement in the joint. $^{5,15,32,47}$ This allows a physiological force to be applied while the foot is allowed to react proprioceptively during extreme dorsiflexion and plantarflexion. ${ }^{32}$ Dorsal and plantar range of motion for the first ray can be effectively measured by this method. To evaluate plantar flexion, the block is placed under the lateral four metatarsals while the first ray is left unsupported. ${ }^{47}$ Dorsiflexion is then evaluated by placing the block under the first ray. This technique has not been tested previously for reliability. ${ }^{5}$ Motion on the horizontal plane can be evaluated using the radiographic squeeze test. ${ }^{47}$ For this test, a strap is used 
to squeeze the forefoot and midfoot together. Anteroposterior radiographs are taken of the foot and are compared between strapped and unstrapped pictures. Hypermobility may be suspected if there is a cuneiform split, where a diastasis occurs between the first metatarsal, second metatarsal, and medial cuneiform during the strapped radiographs. Other structural problems related to the first ray that can be seen on x-ray include the length of the first metatarsal and first metatarsal sesamoid bones that may be located too far posterior. ${ }^{35}$ Hypertrophy of the second metatarsal may also be seen if an increased amount of pressure is put on the second metatarsal. ${ }^{35,36}$

First ray mobility measuring device: An early device was created to measure first ray mobility from the dorsal side of the first ray. ${ }^{2,34}$ The device stabilized the lateral four metatarsals while the first ray was totally free and unsupported. ${ }^{4,34}$ The examiner would then passively thrust the first ray into an unstandardized amount of extension as a micrometer was placed on the dorsal surface of the first ray to measure the amount of displacement. $^{4,34}$ No reliability or validity has been reported for this device. ${ }^{2}$

A second device designed by Rodgers and Cavanaugh ${ }^{2,33}$ to test first ray mobility used a force transducer from the plantar side. ${ }^{2-4}$ The device stabilized the lateral four metatarsals while 90 Newtons $(\mathrm{N})$ of force was placed onto the first ray from the plantar side, dorsally. ${ }^{2}$ Measurements were then taken from the dorsal side and the plantar side of the first metatarsal head. No validity was reported for the device, but moderate to high intratester reliability was reported for dorsal and plantar measurements $(\mathrm{ICC}=0.92$ and 0.67 , respectively). A significant difference $(\mathrm{p}<0.01)$ was found between the two measurements. 
The current first ray mobility measuring device was constructed and improved to be a more accurate and safe method of measuring first ray mobility. ${ }^{19}$ Common features among this device and its predecessors are a boot shape to stabilize the rearfoot and instrumentation to measure the amount of displacement of the first ray. ${ }^{4}$ Additions include a forefoot capture assembly made of stainless steel that allows for height adjustability and for either foot to be used. It is free standing and made out of aluminum. A rearfoot stabilizer is made out of a customized immobilizer boot set on a wooden platform.

The device is used by first placing the foot non-weightbearing in the immobilizer boot with the hip and knee at $90^{\circ}{ }^{4}$ The forefoot capture assembly stabilizes the lateral four metatarsals using a screw-tightened forefoot clamp and keeps the ankle at $90^{\circ}{ }^{4,5}$ The first metatarsal rests on a load cell powered by a Sensotec Model GM signal conditionerindicator. ${ }^{4}$ A Sensotec MVL7 AC-AC linear variable differential transformer, which is powered by a Sensotec Model DM demodulator, is fixed so that it will freely move vertically and effectively measure displacement from the dorsal side of the foot. ${ }^{4,5} \mathrm{~A}$ radiographic study performed by Glasoe et al. ${ }^{5}$ observed that using the device with $55 \mathrm{~N}$ of force had an interclass correlation coefficient $(\mathrm{ICC})=0.91$. Therefore, only $55 \mathrm{~N}$ of force is used to dorsiflex the first ray from the plantar side. ${ }^{4}$ This keeps any unwanted movement of the forefoot or rearfoot from occurring. The device has been found to have an ICC between 0.92 and 0.98 after three trials. ${ }^{4,5,14,19}$ Validity was found to be $\operatorname{good}(\mathrm{F}=0.18){ }^{4}$ Correlation values found when comparing Glasoe's first ray mobility measuring device to manual measurements found no associations $(\mathrm{r}=-0.25) .{ }^{19}$

Reliability Studies 
Only a few studies have examined the reliability of first ray mobility measurements. Glasoe et al.'s ${ }^{19}$ study is the only one that tested the reliability of the manual technique, comparing it to the first ray mobility measuring device. The methods of this study included three examiners; one orthopedic surgeon with 10 years of experience, one physical therapist with 12 years of experience, and one newly graduated physical therapist with less than one year of experience. Using the scale and measuring method described in the study, the three examiners first measured the 15 subjects manually, then by the first ray mobility measuring device. To get intrarater measurements, the examiners left the room while the patients were rearranged on their tables between two measurements. Interrater and intrarater reliability results were analyzed for the manual technique and ICC values were analyzed for the device. The overall intrarater values were 0.73 while the interrater values were much lower $(0.09$ and 0.16$))$. The ICC values for the device were good $(\mathrm{ICC}=0.85)$. Correlation between the surgeon's results and the device's results did not have any association $(\mathrm{r}=-0.25)$. This may indicate that the manual technique and the device may begin measurements from different starting positions.

Glasoe et al. ${ }^{5}$ used 20 cadaveric feet to get the reliability of the first ray mobility measuring device. Three trials were performed on the device to get the best reliability values. Loads applied to the foot on the device included $20 \mathrm{~N}, 35 \mathrm{~N}, 55 \mathrm{~N}$, and $85 \mathrm{~N}$. Radiographic results were also correlated with the results of the device. The reliability results of the device were 0.98 and an ICC of 0.91 was found between radiographs and the device when measured at $55 \mathrm{~N}$, indicating that the device and radiograph results were very similar when $55 \mathrm{~N}$ of force was applied.

Other Reliability Studies 
As indicated before, there are few studies performed on the first ray regarding the reliability of measurement techniques. The purpose of evaluating other reliability studies is to evaluate other methods and data analyses that have been used. Methodology evaluated includes the number and health of the subjects, the examiner's technique, whether the study is blinded, and the number of measurements taken.

Ehrat et al. ${ }^{54}$ completed a study evaluating the reliability of a patellar alignment measuring technique using three examiners with 2000 clinical experience hours each. Each examiner used a standardized technique to measure the A angle on bilateral knees for 34 subjects in two consecutive trials, unblinded. The resulting ICC values were poor for the A angle, ranging from 0.20 to 0.40 .

A reliability study ${ }^{55}$ assessing subtalar joint position was performed using 30 subjects and two examiners. One examiner was a physical therapist and one was a physical therapy student. Two different measurements were taken to assess joint position, including calcaneal position and navicular height. Each measurement was performed twice bilaterally and the examiners were blinded. The measurements were taken using a standardized technique. The resulting ICC values for the calcaneal position $(0.68-0.91)$ and navicular height (0.73-0.96) were very good.

The reliability of static scapular position measurements was assessed in a study performed Gibson et al. ${ }^{56}$ The study used 32 subjects with no history of injury to the shoulder girdle and two undefined examiners. The examiners evaluated three standardized Kibler measurements and one DeVita measurement which all determine static scapular position. Each subject was examined twice, bilaterally, and unblinded. The intratester ICC 
values of each measurement was good (0.81-0.95) while intertester ICC values were low to moderate (0.18-0.69).

Watson et al. ${ }^{21}$ performed a study to assess the reliability of the McConnell classification system of patellar orientation. Fifty-six subjects and two senior physical therapy student testers were used. Each of the testers used a standardized technique, which was practiced prior to the study. The testers examined each knee twice, each measurement several days apart from each other, and were blinded to the presence of knee pain. The resulting kappa coefficients ranged from poor to fair $(K=-0.06$ to 0.35$)$.

White et al. ${ }^{30}$ performed a reliability study on the Movement System Balance (MSB) approach for classification of back pain. This study was the first reliability study performed for this measurement other than the creator of the classification system. Four examiners were used, two who had 3-day continuing education course on the system and two who were only given notes and a video on the system. A standardized technique was used and all examiners evaluated each subject once. Results using kappa statistics ranged from slight to substantial agreement $(K=0.02$ to 0.62$)$.

Treatment

Non-surgical treatment for first ray abnormalities should be attempted prior to any surgical treatment. ${ }^{47}$ In no case should surgery be performed solely for cosmetic reasons. Examples of non-surgical treatments include appropriate shoe wear and orthotics. Shoes should accommodate the problems of the foot with a sufficient shoe size and toe box. A soft leather shoe may be most comfortable for patients with first ray abnormalities. Rigid soles should be used for patients with hypermobility problems, such as hallux valgus.

Rigid or semi rigid orthotics can also be used to treat hallux valgus using a medial distal 
post under the first metatarsal head and a metatarsal pad proximal to the second metatarsal head. If non-surgical treatment does not alleviate pain and keratoses, surgical treatment may then be considered.

Surgical intervention is performed in severe cases of hallux valgus or elevatus primus varus. ${ }^{47}$ Hallux valgus, hallux rigidus, and rheumatoid forefoot deformities with a hypermobile first ray are corrected by a first metatarsophalangeal joint arthrodesis, or Lapidus procedure, of the tarsometatarsal joint. ${ }^{47,57,58}$ An arthrodesis is contraindicated in the case of arthritis of the hallux metatarsophalangeal joint, a short first metatarsal, or an open epiphysis. ${ }^{47}$ Due to bone loss during the resectioning portion of the procedure, shortening of the first metatarsal may occur. ${ }^{43,57}$ This procedure is performed to "correct and stabilize the first metatarsal at the apex of the deformity." ${ }^{\prime 4}$ Currently a Kirschner wire fixation for the first and second metatarsals and a bone graft has increased the chances of good results after this procedure to between $79 \%$ and $90 \% .{ }^{47}$ Neylon et al. ${ }^{57}$ observed that a Lapidus bunionectomy decreased the intermetatarsal angle by $8.6^{\circ}$ and the hallux abductus angle by $17.6^{\circ}$. Coughlin et al. ${ }^{51}$ reported that an osteotomy improved the hallux valgus angle and intermetatarsal angle. Bierman et al. ${ }^{13}$ indicated that a first metatarsocuneiform joint arthrodesis does not affect peroneus longus function on the first ray negatively. The peroneus longus' functions of eversion, plantarflexion, and abduction were slightly increased.

Lengthening the peroneus longus tendon is a surgical intervention for the rigid or non-rigid plantarflexed first ray. ${ }^{9}$ It is used to enhance the outcome of other surgical procedures correcting the plantarflexed first ray. This surgical procedure will most likely result in a loss in at least one grade of strength in the peroneus longus muscle. 


\section{Summary}

Normal motion is required by the first ray to obtain a normal gait cycle. Abnormalities to the first ray can result in numerous problems, ranging from nerve disorders to ligamentous laxity. The first ray includes the first metatarsal and the first cuneiform and all of their articulations. Ligaments, osseous structures, and musculature all aid in the strength and ability of the first ray to complete normal motion. The first ray lies $45^{\circ}$ in the sagittal and frontal planes and slightly away from the transverse plane as a triplanar joint. It is capable of providing shock absorption during heel strike and stability to the foot during the push-off phase of the gait cycle. It plays a large part in the "windlass" effect, which is important for the stability of the foot during push-off. Abnormal biomechanics include hypermobility, hypomobility, a plantarflexed first ray, and a dorsiflexed first ray. These abnormal biomechanics can be the cause of problems such as elevatus primus varus, hallux valgus, metatarsalgia, Morton's neuroma, hallux rigidus, stress fractures, and flat foot deformity. Abnormal biomechanics of the first ray can be caused by diabetes, heredity, ethnicity, footwear, acute trauma, arthritis, osteoarthritis, avascular necrosis, and neuromuscular disorders. Little information is available regarding how common these problems are. Evaluation of the first ray begins with a complete history, inspection, and palpation. Evaluation of the biomechanics of the first ray can be performed using manual techniques, radiographs, or a first ray mobility measuring device. Manual techniques are not very reliable, but are most readily available. Radiographs are less readily available, but appear to be more reliable. First ray mobility measuring devices have the highest reliability, but are not readily available for use. Treatment of biomechanical abnormalities should begin non-surgically. In severe cases of 
hallux valgus, hallux rigidus, and/or forefoot deformities, surgery may be indicated to realign the first metatarsal. This is most commonly performed by the Lapidus procedure, which has a $79 \%-90 \%$ chance of positive results. 
APPENDIX C

ADDITIONAL METHODS

Table C1. Informed Consent

CONSENT AND INFORMATION FORM (EXAMINERS)

\section{Reliability of Position and Mobility of the First Ray in Experienced and Inexperienced Examiners}

\section{Introduction}

I, which has been explained to me by Crystal Shirk, ATC. She is conducting research under the supervision of Michelle A. Sandrey, PhD, ATC to fulfill the requirements for a master's thesis for Athletic Training in the School of Physical Education at West Virginia University.

\section{Purposes of the Study}

The purposes of the study are to evaluate 1) whether or not experienced examiners have a higher reliability of manual testing of first ray mobility than inexperienced examiners and 2) how reliable is this measurement over time. This study should include 50 subjects, four examiners, and four recorders.

\section{Description of this Study}

This study will be conducted at HealthWorks Rehab \& Fitness at 943 Maple Drive, Morgantown, WV 26505.

Orientation Procedures

At an orientation meeting, I will be explained the purpose of this study. I will also be given an informed consent form explaining my rights as a research subject. It will be explained that it is important that I am present for all meetings and for their entirety after the orientation meeting.

Interventions

I will be required to come to one practice and two testing meetings to complete the required testing procedure. The practice meeting will take place at HealthWorks Rehab

$\underline{1-13-04} \quad$ Page 1 of 3

Version date $\overline{\text { initials }}$ date 


\section{Reliability of Position and Mobility of the First Ray in Experienced and Inexperienced Examiners}

$\&$ Fitness 45-60 minutes prior to testing. Test meetings will take place at HealthWorks Rehab \& Fitness.

There will be three other examiners participating in this study. At our practice session, I will practice one method of measuring mobility of the first metatarsal and bone posterior to the first metatarsal (first ray). I will be allowed to practice this method until I am comfortable during this practice meeting. At this meeting the principal investigator will also prepare me for the measurement of the position of the first ray. I understand that this practice meeting may last up to an hour.

I will be led into a room along with the other three examiners at the beginning of each testing meeting so that I will not know the identity of the subjects. The principal investigator will notify me when it is time to come into the room. I will choose a table where one of the four or five subjects is lying, completely covered except for the feet and ankles so that I cannot identify them. I will place the subject's right foot in a neutral position where their toes are neither pointed in nor out (subtalar joint neutral). This will be performed by first using one hand to palpate the bone lying beneath the lower leg bone and above the heel bone on the lateral and medial side of my ankle. Using the opposite hand to grasp the five metatarsals (forefoot) I will manipulate them until subtalar joint neutral is found. I will decide the position of the first ray by whether it lies below the lateral four metatarsals, above them, or even with them. I will quietly notify the recorder assigned to me of my results. To evaluate mobility of the first ray, I will leave the right ankle in subtalar joint neutral. I will grasp and stabilize the lateral four metatarsals with one hand and manipulate the first ray with the other hand. Following Root's technique, I will produce pressure from the bottom and top of the first metatarsal to move it up and down. I will decide if the subject has an excessive mobility (hypermobile), limited mobility (hypomobile), or a normal first ray. I will quietly notify the recorder of my results. After all examiners have completed their evaluation of position and mobility of the right foot, I will move from my current table to the next table to my right with a subject lying on it. I will follow the same procedures as described above on the right foot for each subject in the room. When all right feet have been evaluated, I will begin with the same subject that I started with and evaluate the left foot of every subject in the room. I understand that each testing meeting may take up to five hours to complete.

\section{Risks and Discomforts}

There are no known or expected risks or discomforts from participating in this study. If any injury should occur during the participation of this study, I understand that Crystal Shirk, ATC will provide first aid and make any necessary medical referrals.

\section{Alternative}

I understand that I do not have to participate in this study. $\underline{1-13-04} \quad$ Page 2 of 3

Version date

$$
\overline{\text { Initials }} \quad \overline{\text { Date }}
$$




\section{Reliability of Position and Mobility of the First Ray in Experienced and Inexperienced Examiners}

\section{$\underline{\text { Benefits }}$}

I understand that this study is not expected to be of direct benefit to me, but the knowledge gained may be of benefit to others.

\section{Financial Considerations}

I will receive no financial remuneration for completing this study.

\section{Contact Persons}

For more information about this research, I can contact Crystal Shirk, ATC at (304) 598-3826 or at clshirk@juno.com or her faculty advisor, Michelle A. Sandrey, PhD, ATC at (304) 293-3295 Ext. 5220 or at msandrey@mail.wvu.edu. For information regarding my rights as a research subject, I may contact the Executive Secretary of the Review Board at (304) 293-7073.

\section{Confidentiality}

I understand that any information about me obtained as a result of my participation in this research will be kept as confidential as legally possible. Identifying information on the informed consent form and demographic/injury history questionnaire will be kept confidential by assigning a code number to each informed consent form and demographic/injury history questionnaire. I understand that my research records and test results, just like hospital records, may be subpoenaed by court order or may be inspected by the study sponsor or federal regulatory authorities (including the FDA if applicable) without my additional consent. In any publications that result from this research, neither my name nor any information from which I might be identified will be published without my consent.

\section{Voluntary Participation}

Participation in this study is voluntary. I understand that I am free to withdraw my consent to participate in this study at any time and that such refusal to participate will not affect my future care, my employee status at West Virginia University, or my class standing or grades. Refusal to participate or withdrawal will involve no penalty to me. I have been given the opportunity to ask questions about the research, and I have received answers concerning areas I did not understand. In the event new information becomes available that may affect my willingness to continue to participate in this study, this information will be given to me so I may make an informed decision about my participation.

Upon signing this form, I will receive a copy.

I willingly consent to participate in this research.

\begin{tabular}{|c|c|c|}
\hline Signature of Subject & Date & Time \\
\hline Signature of Principal Investigator & Date & Time \\
\hline$\underline{1-13-04}$ & Page 3 of 3 & \\
\hline$\overline{\text { Version date }}$ & & \\
\hline
\end{tabular}


Table C2. Informed Consent

\title{
CONSENT AND INFORMATION FORM (RECORDERS)
}

\author{
Reliability of Position and Mobility of the First Ray \\ in Experienced and Inexperienced Examiners
}

\section{Introduction}

$\mathrm{I}$, , have been invited to participate in this research study, which has been explained to me by Crystal Shirk, ATC. She is conducting research under the supervision of Michelle A. Sandrey, $\mathrm{PhD}, \mathrm{ATC}$ to fulfill the requirements for a master's thesis for Athletic Training in the School of Physical Education at West Virginia University.

\section{Purposes of the Study}

The purposes of the study are to evaluate 1) whether or not experienced examiners have a higher reliability of manual testing of first ray mobility than inexperienced examiners and 2) how reliable is this measurement over time. This study should include 50 subjects, four examiners, and four recorders.

\section{Description of this Study}

This study will be conducted at HealthWorks Rehab \& Fitness at 943 Maple Drive, Morgantown, WV 26505.

\section{Orientation Procedures}

At an orientation meeting, I will be explained the purpose of this study. I will also be given an informed consent form explaining my rights as a research subject and a copy of the data sheet that I will be recording onto. It will be explained that it is important that I am present for both meetings and for their entirety after the orientation meeting.

\section{Interventions}

I will be required to come to two meetings to complete the required testing procedure. I will show up at least 15 minutes prior to each meeting at HealthWorks Rehab \& Fitness and will be allowed to leave after the last subjects have left. I will perform the same duties at each meeting. I will be given a pen and clipboard with data recording sheets to record all data for one examiner. Three other recorders will be participating in this study.

Two data sheets will have enough columns to record data for all subjects for one

1-13-04

Version date
Page 1 of 3

$$
\overline{\text { Initials }} \overline{\text { date }}
$$




\section{Reliability of Position and Mobility of the First Ray in Experienced and Inexperienced Examiners}

examiner. A different sheet will be used for each examiner. The sheet will be allow position and mobility measurements. Columns for 25 subjects will be available on each page for data collection. No subjects' names will be used on the sheet, but corresponding numbers to each subject's name that will be randomly chosen prior to the meeting. Each subject will have two rows, one for right and one for the left foot. Two columns will be used for each subject, one for position and one for mobility. The data sheet will be completed from top to bottom for column one and the same for column two. No examiner's names will be used on the sheet, but corresponding numbers to each examiner that will be randomly chosen prior to the meeting.

For the entire time that the subjects are at HealthWorks Rehab \& Fitness, I will maintain the hidden identity of the subjects from the examiners. I will rotate from table to table with the examiner that I am assigned to. After each measurement, I will record the examiner's result in coding for position $(\mathrm{DF}=$ dorsiflexed, $\mathrm{PF}=$ plantarflexed, and Norm=normal) and for mobility (Hypo=hypomobile, Hyper=hypermobility, and Norm=normal). I will quietly communicate with the examiner for their results to keep the other three examiners in the room from knowing each other's results. After each data sheet is complete, I will place the used data sheet in a designated folder that will be give to the principal investigator at the end of the meeting. I understand that each of these meetings may last up to five hours.

\section{Risks and Discomforts}

There are no known or expected risks or discomforts from participating in this study. If any injury should occur during the participation of this study, I understand that Crystal Shirk, ATC will provide first aid and make any necessary medical referrals.

\section{Alternative}

I understand that I do not have to participate in this study.

\section{$\underline{\text { Benefits }}$}

I understand that this study is not expected to be of direct benefit to me, but the knowledge gained may be of benefit to others.

\section{Financial Considerations}

I will receive no financial remuneration for completing this study.

1-13-04

Version date
Page 2 of 3

initials date 


\section{Reliability of Position and Mobility of the First Ray in Experienced and Inexperienced Examiners}

\section{Contact Persons}

For more information about this research, I can contact Crystal Shirk, ATC at (304) 598-3826 or at clshirk@juno.com or her faculty advisor, Michelle A. Sandrey, PhD, ATC at (304) 293-3295 Ext. 5220 or at msandrey@mail.wvu.edu. For information regarding my rights as a research subject, I may contact the Executive Secretary of the Review Board at (304) 293-7073.

\section{Confidentiality}

I understand that any information about me obtained as a result of my participation in this research will be kept as confidential as legally possible. Identifying information on the informed consent form and demographic/injury history questionnaire will be kept confidential by assigning a code number to each informed consent form and demographic/injury history questionnaire. I understand that my research records and test results, just like hospital records, may be subpoenaed by court order or may be inspected by the study sponsor or federal regulatory authorities (including the FDA if applicable) without my additional consent. In any publications that result from this research, neither my name nor any information from which I might be identified will be published without my consent.

\section{Voluntary Participation}

Participation in this study is voluntary. I understand that I am free to withdraw my consent to participate in this study at any time and that such refusal to participate will not affect my future care, my employee status at West Virginia University, or my class standing or grades. Refusal to participate or withdrawal will involve no penalty to me. I have been given the opportunity to ask questions about the research, and I have received answers concerning areas I did not understand. In the event new information becomes available that may affect my willingness to continue to participate in this study, this information will be given to me so I may make an informed decision about my participation.

Upon signing this form, I will receive a copy.

I willingly consent to participate in this research.

Signature of Subject

Signature of Principal Investigator
Date

Date
Time

Time
1-13-04

Version date
Page 3 of 3 date 
Table C3. Informed Consent

\title{
CONSENT AND INFORMATION FORM (SUBJECTS)
}

\author{
Reliability of Position and Mobility of the First Ray \\ in Experienced and Inexperienced Examiners
}

\section{$\underline{\text { Introduction }}$}

I, , have been invited to participate in this research study, which has been explained to me by Crystal Shirk, ATC. She is conducting research under the supervision of Michelle A. Sandrey, $\mathrm{PhD}$, ATC to fulfill the requirements for a master's thesis for Athletic Training in the School of Physical Education at West Virginia University.

\section{Purposes of the Study}

The purposes of the study are to evaluate 1) whether or not experienced examiners have a higher reliability of manual testing of first ray mobility than inexperienced examiners and 2) how reliable is this measurement over time. This study should include 50 subjects, four examiners, and four recorders.

\section{Description of this Study}

This study will be conducted at HealthWorks Rehab \& Fitness at 943 Maple Drive, Morgantown, WV 26505.

Orientation Procedures

At an orientation meeting, I will be explained the purpose of this study. I will also be given an informed consent form and a demographic/injury history questionnaire explaining my rights as a research subject.

If I am an eligible student, I will sign up for a time slot on both days that the study will take place. I will be asked for my full cooperation and that I show up on time for both time slots.

Interventions

I will show up for my allotted time slot at HealthWorks Rehab \& Fitness. There will be three or four other subjects showing up at the same time as I do to be tested. I will be brought to the treatment area in the clinic and asked to lie on my back on a treatment table with my ankles and feet hanging off the end. The principal investigator will use a curtain to cover my body

$\underline{1-13-04} \quad$ Page 1 of 3

Version date

$\overline{\text { initials }} \overline{\text { date }}$ 


\section{Reliability of Position and Mobility of the First Ray in Experienced and Inexperienced Examiners}

except for my ankles and feet. The examiners will then come into the room, not knowing the subjects they are evaluating nor the results that are obtained by other examiners in the room. The examiners will then place my foot in a neutral position where my toes are neither pointed in nor out (subtalar joint neutral). To do this, the examiner must use one hand to palpate the bone lying beneath the lower leg bone and above the heel bone on the lateral and medial side of my ankle. With the opposite hand the examiner will grasp my five metatarsals (forefoot) and manipulate them until subtalar joint neutral is found. The examiner will then observe the position of my first metatarsal and bone posterior to the first metatarsal (first ray).

Measurement of the first ray will also be performed while my foot is in subtalar joint neutral. The examiner will grasp and stabilize the lateral four metatarsals with one hand and manipulate the first ray with the other hand. This will allow the examiner to decide if I have excessive mobility (hypermobile), limited mobility (hypomobile), or a normal first ray. All four examiners will rotate to observe position and test mobility of my right first ray first, then my left first ray. I understand that I will not know the decision made by the examiners about the mobility of my first ray when I leave. I understand that West Virginia University researchers hope to enroll approximately 50 subjects in this study. I further understand that the approximate time to complete each meeting is 20-minutes.

\section{Risks and Discomforts}

There are no known or expected risks from participating in this study. This evaluation is used in the clinical setting on a daily basis. There may be some discomfort during the manipulation of the first ray, but I understand that if excessive pain is caused that I may indicate to the examiner that too much pressure is being applied. I understand that every precaution has been taken to prevent me from being injured during this study. If any injury should occur during the participation of this study, I understand that Crystal Shirk, ATC will provide first aid and make any necessary medical referrals.

\section{Alternative}

I understand that I do not have to participate in this study.

\section{Benefits}

I understand that this study is not expected to be of direct benefit to me, but the knowledge gained may be of benefit to others.

$\frac{1-13-04}{\text { Version date }}$

Page 2 of 3

initials

date 


\section{Reliability of Position and Mobility of the First Ray in Experienced and Inexperienced Examiners}

\section{Financial Considerations}

I will receive no financial remuneration for completing this study.

\section{Contact Persons}

For more information about this research, I can contact Crystal Shirk, ATC at (304) 598-3826 or at clshirk@juno.com or her faculty advisor, Michelle A. Sandrey, PhD, ATC at (304) 293-3295 Ext. 5220 or at msandrey@mail.wvu.edu. For information regarding my rights as a research subject, I may contact the Executive Secretary of the Review Board at (304) 293-7073.

\section{Confidentiality}

I understand that any information about me obtained as a result of my participation in this research will be kept as confidential as legally possible. Identifying information on the informed consent form and demographic/injury history questionnaire will be kept confidential by assigning a code number to each informed consent form and demographic/injury history questionnaire. I understand that my research records and test results, just like hospital records, may be subpoenaed by court order or may be inspected by the study sponsor or federal regulatory authorities (including the FDA if applicable) without my additional consent. In any publications that result from this research, neither my name nor any information from which I might be identified will be published without my consent.

\section{Voluntary Participation}

Participation in this study is voluntary. I understand that I am free to withdraw my consent to participate in this study at any time and that such refusal to participate will not affect my future care, my employee status at West Virginia University, or my class standing or grades. Refusal to participate or withdrawal will involve no penalty to me. I have been given the opportunity to ask questions about the research, and I have received answers concerning areas I did not understand. In the event new information becomes available that may affect my willingness to continue to participate in this study, this information will be given to me so I may make an informed decision about my participation.

Upon signing this form, I will receive a copy.

I willingly consent to participate in this research.

Signature of Subject

Signature of Principal Investigator

\section{Date}

Date
Time

Time

1-13-04

Page 3 of 3

Version date

initials

date 
Table C4. Demographic/Injury History Questionnaire

\section{Demographics}

Name:

Age:

Gender: Male/Female

Year in School: Freshman/Sophomore/Junior/Senior/Graduate Student

Injury History

1. Have you had an injury to the ankle or foot within the past six months? Yes/No

If yes, please explain:

2. Have you had any neurological disorders within the past six months affecting the lower extremity? Yes/No

If yes, please explain:

3. Have you ever had any surgeries performed on your feet? Yes/No

If yes, please explain, including dates of surgeries:

4. Have you been diagnosed with any foot disorders/deformities such as hallux valgus (bunion), hallux limitus (limited movement of the first toe), or any other disorders/deformities? Yes/No

If yes, please explain:

5. Do you have diabetes mellitus or any other disease decreasing sensation in the foot? Yes/No

If yes, please describe any problems with sensation that you may be experiencing:

6. Do you wear orthotics or other prescribed inserts in your shoes? Yes/No

If yes, please explain: 
Table C5. Procedures for Evaluation of First Ray Position

1. The examiner will place the right ankle in subtalar joint neutral

2. The examiner will then place one thumb on the plantar side of the foot just proximal to the first metatarsal head and the other thumb on the plantar side of the foot just proximal to the lateral four metatarsal heads without applying any pressure.

3. The examiner will observe the first ray on the right foot in comparison to the lateral four metatarsals.

4. The examiner will then decide if the first ray is plantarflexed, dorsiflexed, or even in comparison to the lateral four metatarsals.

5. A plantarflexed first ray will be considered if the first ray is plantarflexed at a larger degree than it is dorsiflexed. ${ }^{8}$

6. A dorsiflexed first ray will be considered if the first ray is dorsiflexed at a larger degree than it is plantarflexed. ${ }^{8}$

7. A normal first ray will be considered if the first ray is dorsiflexed the same amount as it is plantarflexed. ${ }^{8}$

8. Each examiner will quietly report their decision to the recorder so that the results are blinded to other examiners in the room.

9. Each examiner will wait at their table until all examiners have completed measuring position and mobility of the first ray on the right foot.

10. Each examiner will rotate to their right to evaluate position and mobility of the first ray on the right foot on the next subject.

11. This will continue until each examiner has evaluated the first ray of the right foot on all subjects in the room.

12. The examiners will follow the same procedures as before to evaluate position of the first ray on the left foot of all subjects, beginning with the same first subject. 
Table C6. Procedures for Evaluation of First Ray Mobility; Root's Technique ${ }^{7}$

1. The examiner will place the right ankle in subtalar joint neutral.

2. The examiner will stabilize the lateral four metatarsals with one hand.

3. The thumb will be placed on the plantar side of the foot, lying across the metatarsal heads, while the $2^{\text {nd }}-5^{\text {th }}$ fingers will stabilize on the dorsal side of the lateral four metatarsals.

4. The examiner will use the opposite hand to grasp the first ray.

5. The thumb will be placed on the plantar side of the head of the first metatarsal while the $2^{\text {nd }}-5^{\text {th }}$ fingers will be placed on the dorsal side of the first metatarsal.

6. The thumb holding the first metatarsal will then produce a dorsal force on the sagittal and frontal plane until the examiner feels an endpoint.

7. The index finger holding the first metatarsal will then produce a plantar force on the sagittal and frontal plane until the examiner feels an endpoint.

8. The first ray will be considered hypermobile if the amount of dorsal movement is greater than the amount of plantar movement.

9. The first ray will be considered hypomobile if the amount of dorsal movement is less than the amount of plantar movement.

10. The first ray will be considered normal if the amount of dorsal movement and plantar movement is the same.

11. Each examiner will quietly indicate their decision to the recording assistant as to blind other examiners from their results.

12. Each examiner will wait until all examiners have completed their examination of the subject and reported their results.

13. Each examiner will rotate to the subject to the right of their table and follow procedures as described above for the right foot until all subjects in the room have been evaluated.

14. The examiners will follow the same procedures to measure mobility of the first ray on the left foot of all subjects, beginning with the same first subject.

Table C7. Procedures for Placing the Ankle in Subtalar Joint Neutral

1. With one hand, palpate the talus on both sides of the ankle.

2. With the opposite hand, gently grasp the forefoot.

3. Rotate the forefoot back and forth on the transverse plane slowly until the talus can be felt equally on both sides, or when the calcaneus is perpendicular to the ground and parallel to the distal $1 / 3$ of the leg. ${ }^{8}$

4. Slightly dorsiflex the ankle while in this position. 
Table C8. Recording Sheet for Position and Mobility of the First Ray

\begin{tabular}{|c|c|c|c|c|c|}
\hline Examiner: & & & & Date: & \\
\hline & Position & Mobility & & Position & Mobility \\
\hline Subject1 & & & Subject14 & & \\
\hline & $\mathrm{L}_{-}$ & $\mathrm{L}_{-}$ & & L & $\mathrm{L}_{-}$ \\
\hline Subject2 & $\mathrm{R}$ & R & Subject15 & $\mathrm{R}_{-}$ & R \\
\hline & $\mathrm{L}_{-}$ & $\mathrm{L}_{-}$ & & $\mathrm{L}_{-}^{-}$ & $\mathrm{L}_{-}^{-}$ \\
\hline Subject3 & $\mathrm{R}$ & $\mathrm{R}$ & Subject16 & $\mathrm{R}$ & $\mathrm{R}$ \\
\hline & $\mathrm{L}_{-}$ & $\mathrm{L}_{-}$ & & $\mathrm{L}_{-}$ & $\mathrm{L}_{-}$ \\
\hline Subject4 & $\mathrm{R}_{-}$ & $\mathrm{R}_{-}$ & Subject17 & $\mathrm{R}_{-}$ & $\mathrm{R}_{-}$ \\
\hline & $\mathrm{L}_{-}$ & $\mathrm{L}_{-}$ & & $\mathrm{L}_{-}$ & $\mathrm{L}_{-}$ \\
\hline Subject5 & $\mathrm{R}$ & $\mathrm{R}_{-}$ & Subject 18 & $\mathrm{R}$ & $\mathrm{R}$ \\
\hline & $\mathrm{L}_{-}$ & $\mathrm{L}_{-}$ & & $\mathrm{L}_{-}^{-}$ & $\mathrm{L}_{-}$ \\
\hline Subject6 & $\mathrm{R}$ & $\mathrm{R}$ & Subject19 & $\mathrm{R}$ & $\mathrm{R}$ \\
\hline & $\mathrm{L}_{-}$ & $\mathrm{L}_{-}$ & & $\mathrm{L}_{-}$ & $\mathrm{L}_{-}$ \\
\hline Subject7 & $\mathrm{R}_{-}$ & $\mathrm{R}_{-}$ & Subject 20 & $\mathrm{R}_{-}$ & $\mathrm{R}_{-}$ \\
\hline & $\mathrm{L}_{-}$ & $\mathrm{L}_{-}$ & & $\mathrm{L}_{-}$ & $\mathrm{L}_{-}$ \\
\hline Subject8 & $\mathrm{R}_{-}$ & $\mathrm{R}_{-}$ & Subject 21 & $\mathrm{R}_{-}$ & $\mathrm{R}_{-}$ \\
\hline & $\mathrm{L}_{-}$ & $\mathrm{L}_{-}$ & & $\mathrm{L}_{-}$ & $\mathrm{L}_{-}$ \\
\hline Subject9 & $\mathrm{R}$ & $\mathrm{R}$ & Subject22 & $\mathrm{R}_{-}$ & $\mathrm{R}$ \\
\hline & $\mathrm{L}_{-}$ & $\mathrm{L}_{-}$ & & $\mathrm{L}_{-}$ & $\mathrm{L}_{-}$ \\
\hline Subject10 & $\mathrm{R}_{-}$ & $\mathrm{R}_{-}$ & Subject 23 & $\mathrm{R}_{-}$ & $\mathrm{R}_{-}$ \\
\hline & $\mathrm{L}_{-}$ & $\mathrm{L}_{-}$ & & $\mathrm{L}_{-}$ & $\mathrm{L}_{-}$ \\
\hline Subject11 & $\mathrm{R}$ & $\mathrm{R}$ & Subject24 & $\mathrm{R}$ & $\mathrm{R}$ \\
\hline & $\mathrm{L}_{-}$ & $\mathrm{L}_{-}$ & & $\mathrm{L}_{-}$ & $\mathrm{L}_{-}$ \\
\hline Subject12 & $\mathrm{R}_{-}$ & $\mathrm{R}_{-}$ & Subject 25 & $\mathrm{R}_{-}$ & $\mathrm{R}$ \\
\hline & $\mathrm{L}_{-}$ & $\mathrm{L}_{-}$ & & $\mathrm{L}_{-}$ & $\mathrm{L}_{-}$ \\
\hline Subject13 & $\mathrm{R}_{-}$ & $\mathrm{R}_{-}$ & & & \\
\hline & $\mathrm{L}$ & $\mathrm{L}$ & & & \\
\hline
\end{tabular}

CODES:

Position: Plantarflexed=PF, Dorsiflexed $=\mathrm{DF}$, Normal $=$ Norm

Mobility: Hypermobility=Hyper, Hypomobility=Hypo, Normal=Norm 


\begin{tabular}{|c|c|c|c|c|c|}
\hline & \multirow[b]{2}{*}{$\begin{array}{l}\text { Position } \\
\mathrm{R} \\
\mathrm{L}\end{array}$} & \multirow[b]{2}{*}{$\begin{array}{l}\text { Mobility } \\
\mathrm{R} \\
\mathrm{L}\end{array}$} & \multirow[b]{2}{*}{ Subject39 } & \multicolumn{2}{|l|}{ Date: } \\
\hline Subject26 & & & & $\begin{array}{l}\text { Position } \\
\mathrm{R} \\
\end{array}$ & $\begin{array}{l}\text { Mobility } \\
\mathrm{R} \\
\end{array}$ \\
\hline Subject 27 & $\begin{array}{l}\mathrm{R} \\
\mathrm{L}\end{array}$ & $\begin{array}{l}\mathrm{R} \\
\mathrm{L}\end{array}$ & Subject 40 & $\begin{array}{l}\mathrm{R}_{-} \\
\mathrm{L}\end{array}$ & $\begin{array}{l}\mathrm{R}_{-} \\
\mathrm{L}\end{array}$ \\
\hline Subject 28 & $\begin{array}{l}\mathrm{R} \\
\mathrm{L}\end{array}$ & $\begin{array}{l}\mathrm{R} \\
\mathrm{L}\end{array}$ & Subject41 & $\begin{array}{l}\mathrm{R}_{-} \\
\mathrm{L}_{-}\end{array}$ & $\begin{array}{l}\mathrm{R}_{-} \\
\mathrm{L}_{-}\end{array}$ \\
\hline Subject29 & $\begin{array}{l}\mathrm{R} \\
\mathrm{L}\end{array}$ & $\begin{array}{l}\mathrm{R} \\
\mathrm{L}\end{array}$ & Subject 42 & $\begin{array}{l}\mathrm{R}_{-} \\
\mathrm{L}_{-}\end{array}$ & $\begin{array}{l}\mathrm{R}_{-} \\
\mathrm{L}_{-}\end{array}$ \\
\hline Subject30 & $\begin{array}{l}\mathrm{R} \\
\mathrm{L}\end{array}$ & $\begin{array}{l}\mathrm{R} \\
\mathrm{L}\end{array}$ & Subject43 & $\begin{array}{l}\mathrm{R}_{-} \\
\mathrm{L}_{-}\end{array}$ & $\begin{array}{l}\mathrm{R}_{-} \\
\mathrm{L}_{-}\end{array}$ \\
\hline Subject31 & $\begin{array}{l}\mathrm{R}_{-} \\
\mathrm{L}\end{array}$ & $\begin{array}{l}\mathrm{R}_{-} \\
\mathrm{L}_{-}\end{array}$ & Subject44 & $\begin{array}{l}\mathrm{R}_{-} \\
\mathrm{L}_{-}\end{array}$ & $\begin{array}{l}\mathrm{R}_{-} \\
\mathrm{L}_{-}\end{array}$ \\
\hline Subject32 & $\begin{array}{l}\mathrm{R} \\
\mathrm{L}\end{array}$ & $\begin{array}{l}\mathrm{R}_{-} \\
\mathrm{L}_{-}\end{array}$ & Subject45 & $\begin{array}{l}\mathrm{R}_{-} \\
\mathrm{L}_{-}\end{array}$ & $\begin{array}{l}\mathrm{R}_{-} \\
\mathrm{L}_{-}\end{array}$ \\
\hline Subject33 & $\begin{array}{l}\mathrm{R} \\
\mathrm{L}\end{array}$ & $\begin{array}{l}\mathrm{R} \\
\mathrm{L}\end{array}$ & Subject46 & $\begin{array}{l}\mathrm{R}_{-} \\
\mathrm{L}_{-}\end{array}$ & $\begin{array}{l}\mathrm{R} \\
\mathrm{L}\end{array}$ \\
\hline Subject34 & $\begin{array}{l}\mathrm{R} \\
\mathrm{L}\end{array}$ & $\begin{array}{l}\mathrm{R}_{-} \\
\mathrm{L}_{-}\end{array}$ & Subject 47 & $\begin{array}{l}\mathrm{R}_{-} \\
\mathrm{L}_{-}\end{array}$ & $\begin{array}{l}\mathrm{R}_{-} \\
\mathrm{L}_{-}\end{array}$ \\
\hline Subject35 & $\begin{array}{l}\mathrm{R} \\
\mathrm{L}\end{array}$ & $\begin{array}{l}\mathrm{R}_{-} \\
\mathrm{L}_{-}\end{array}$ & Subject48 & $\begin{array}{l}\mathrm{R}_{-} \\
\mathrm{L}_{-}\end{array}$ & $\begin{array}{l}\mathrm{R} \\
\mathrm{L}_{-}\end{array}$ \\
\hline Subject36 & $\begin{array}{l}\mathrm{R} \\
\mathrm{L}\end{array}$ & $\begin{array}{l}\mathrm{R} \\
\mathrm{L}\end{array}$ & Subject49 & $\begin{array}{l}\mathrm{R}_{-} \\
\mathrm{L}_{-}\end{array}$ & $\begin{array}{l}\mathrm{R} \\
\mathrm{L}\end{array}$ \\
\hline Subject37 & $\begin{array}{l}\mathrm{R} \\
\mathrm{L}\end{array}$ & $\begin{array}{l}\mathrm{R}_{-} \\
\mathrm{L}_{-}\end{array}$ & Subject50 & $\begin{array}{l}\mathrm{R}_{-} \\
\mathrm{L}_{-}\end{array}$ & $\begin{array}{l}\mathrm{R}_{-} \\
\mathrm{L}_{-}\end{array}$ \\
\hline Subject38 & $\begin{array}{l}\mathrm{R} \\
\mathrm{L}\end{array}$ & $\begin{array}{l}\mathrm{R} \\
\mathrm{L}\end{array}$ & & & \\
\hline
\end{tabular}

CODES:

Position: Plantarflexed=PF, Dorsiflexed $=$ DF, Normal $=$ Norm

Mobility: Hypermobility=Hyper, Hypomobility=Hypo, Normal=Norm 
Figure C1. First Ray

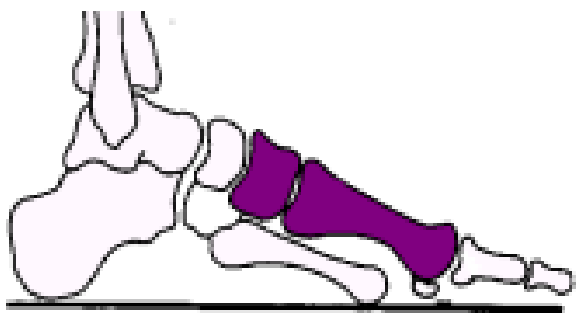

A.

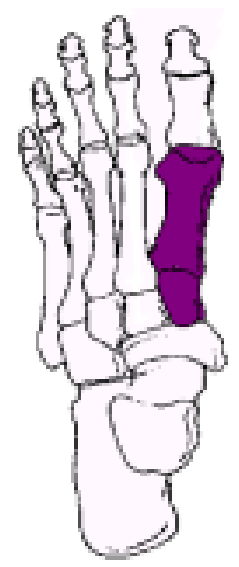

B.

First metatarsal and first cuneiform from a A.lateral view and a B.dorsal view. ${ }^{10}$

Figure C2. Subtalar Joint Neutral
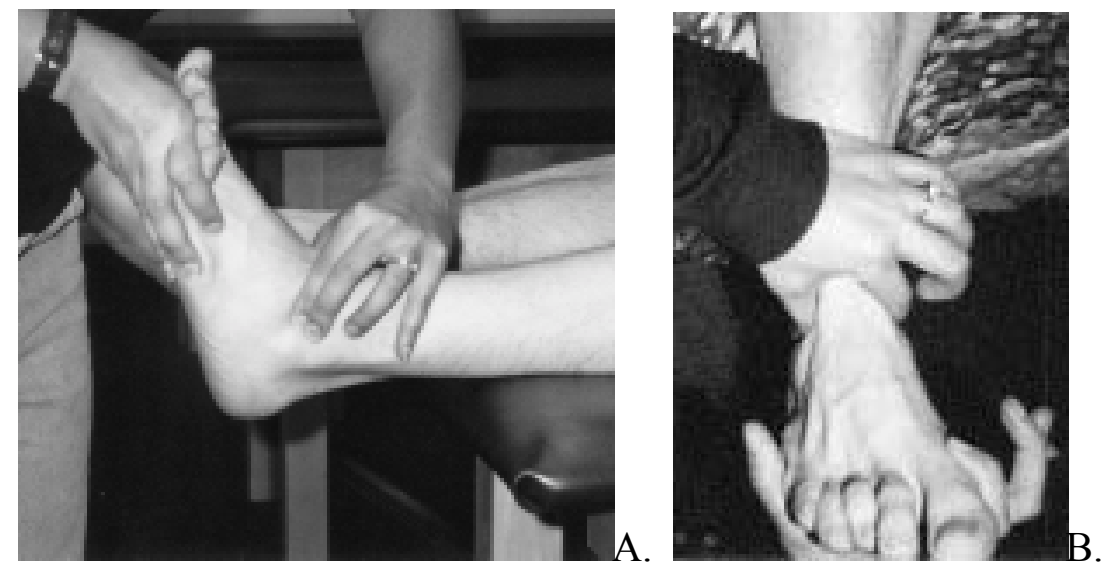

A.Lateral and B.Superior views of subtalar joint neutral with subject lying supine. 
Figure C3. First Ray Position Test

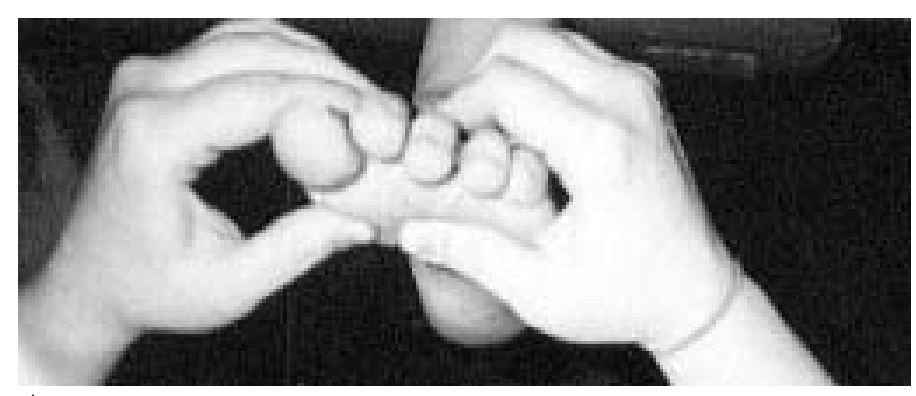

A.

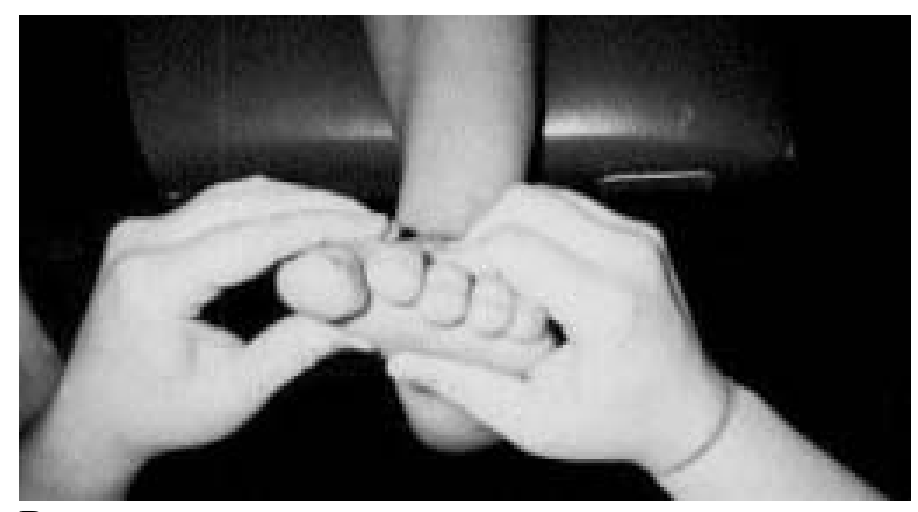

B.

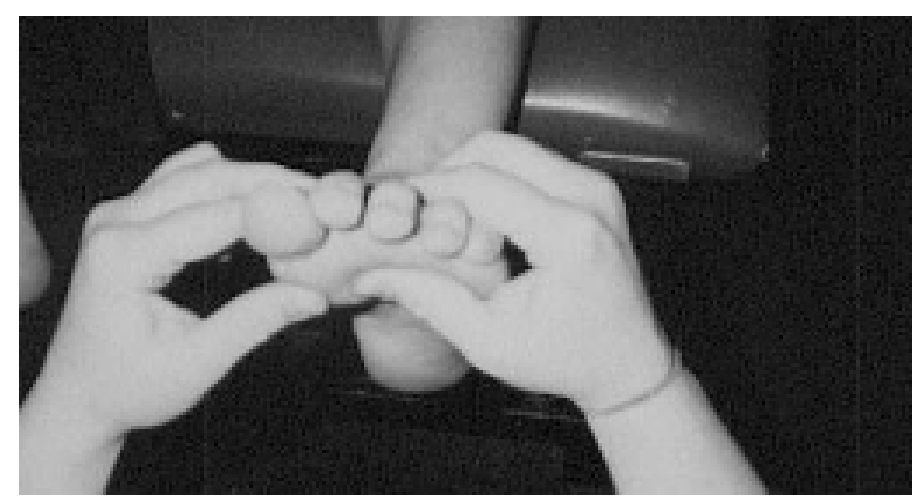

C.

Superior view of a first ray during position testing that is A.Normal, B.Dorsiflexed, and C.Plantarflexed. 


\section{APPENDIX D}

\section{ADDITIONAL RESULTS}

Table D1. Intrarater Reliability of First Ray Position Test.

\begin{tabular}{lccccc}
\hline Examiner & $\begin{array}{c}\text { Agreement } \\
(\mathbf{\%})\end{array}$ & $\begin{array}{c}\text { Kappa } \\
\mathbf{( 9 5 \%} \mathbf{C})\end{array}$ & $\mathbf{P}-$ Value & $\mathbf{K}_{\max }$ & $\begin{array}{c}\mathbf{K} / \mathbf{K}_{\max } \\
\mathbf{( \% )}\end{array}$ \\
\hline I1 & 67 & 0.000 & 0.930 & .28 & 00 \\
I2 & 49 & 0.235 & $0.002^{*}$ & .55 & 42.7 \\
E1 & 50 & 0.262 & $0.001^{* *}$ & .65 & 40.3 \\
E2 & 42 & 0.128 & 0.098 & .62 & 20.6 \\
\hline
\end{tabular}

$\mathrm{I}=$ Inexperienced; $\quad \mathrm{E}=$ Experienced

$\mathrm{N}=72$

$* \mathrm{P} \leq 0.01$

$* * \mathrm{P} \leq 0.001$

Table D2. Intrarater Distributions for Position Testing.

\begin{tabular}{llcccc}
\hline \multirow{2}{*}{ I1-Day 1 } & & & \multicolumn{1}{l}{ I1-Day 2 } & & \\
& & Plantarflexed & Dorsiflexed & Normal & Total \\
\cline { 3 - 6 } & 1 & 1 & 2 & 4 \\
& Dorsiflexed & & & 4 & 4 \\
Total & Normal & 13 & 4 & 47 & 64 \\
\hline
\end{tabular}

I2-Day 2

I2-Day 1

Plantarflexed

Plantarflexed Dorsiflexed Normal Total

Dorsiflexed

16

Normal

9

18

3

2

$2 \quad 21$

Total

43

$\begin{array}{lll}6 & 4 & 19\end{array}$

$\begin{array}{lll}1 & 13 & 32\end{array}$

10

19

72

E1-Day 2

\begin{tabular}{|c|c|c|c|c|c|}
\hline \multirow[t]{4}{*}{ E1-Day 1} & & \multicolumn{2}{|c|}{ Plantarflexed Dorsiflexed } & Normal & Tota \\
\hline & Plantarflexed & 8 & 1 & 2 & 11 \\
\hline & Dorsiflexed & 5 & 20 & 14 & \\
\hline & Normal & 13 & 1 & 8 & \\
\hline Total & & 26 & 22 & 24 & \\
\hline
\end{tabular}

E2-Day 2

E2-Day 1

Plantarflexed Dorsiflexed Normal Total

$\begin{array}{lcccc}\text { Plantarflexed } & 15 & 6 & 4 & 25 \\ \text { Dorsiflexed } & 18 & 8 & 8 & 34 \\ \text { Normal } & 4 & 2 & 7 & 13 \\ & 37 & 16 & 19 & 72\end{array}$


Table D3. Interrater Reliability of First Ray Position Test.

\begin{tabular}{lccccc}
\hline Examiner & $\begin{array}{c}\text { Agreement } \\
(\mathbf{\%})\end{array}$ & $\begin{array}{c}\text { Kappa } \\
(\mathbf{9 5 \%} \mathbf{C})\end{array}$ & $\mathbf{P - V a l u e}$ & $\mathbf{K}_{\mathbf{m a x}}$ & $\begin{array}{c}\mathbf{K} / \mathbf{K}_{\max } \\
\mathbf{( \% )}\end{array}$ \\
\hline Day 1 & & & & & \\
I1 x I2 & 44 & 0.032 & 0.553 & .22 & 14.5 \\
I1 x E1 & 43 & 0.007 & 0.875 & .16 & 4.4 \\
I1 x E2 & 22 & 0.020 & 0.558 & .11 & 18.2 \\
I2 x E1 & 39 & 0.097 & 0.203 & .56 & 17.3 \\
I2 x E2 & 40 & 0.139 & 0.062 & .36 & 38.6 \\
E1 x E2 & 43 & 0.105 & 0.188 & .69 & 15.2 \\
& & & & & \\
Day 2 & & & & & \\
I1 x I2 & 42 & 0.142 & $0.025^{*}$ & .30 & 47.3 \\
I1 x E1 & 32 & 0.000 & 0.695 & .39 & 00 \\
I1 x E2 & 32 & 0.014 & 0.821 & .32 & 4.3 \\
I2 x E1 & 40 & 0.087 & 0.267 & .35 & 24.8 \\
I2 x E2 & 51 & 0.180 & $0.035^{*}$ & .86 & 20.9 \\
E1 x E2 & 26 & 0.000 & 0.148 & .77 & 00 \\
\hline
\end{tabular}

$\mathrm{I}=$ Inexperienced; $\quad \mathrm{E}=$ Experienced

$\mathrm{N}=72$

$* \mathrm{P} \leq 0.05$ 
Table D4. Interrater Distributions for Position Testing on Day 1.

\begin{tabular}{|c|c|c|c|c|c|}
\hline \multirow{4}{*}{ I1-Day 1} & \multicolumn{5}{|c|}{ I2-Day 1} \\
\hline & Plantarflexed & 1 & 1 & 2 & 4 \\
\hline & Dorsiflexed & 1 & 2 & 1 & 4 \\
\hline & Normal & 19 & 16 & 29 & 64 \\
\hline Total & & 21 & 19 & 32 & 72 \\
\hline I1-Day 1 & & Plantarflexe & $\begin{array}{l}\text { E1-Day 1 } \\
\text { Dorsiflexed }\end{array}$ & Normal & Total \\
\hline & Plantarflexed & 1 & & 3 & 4 \\
\hline & Dorsiflexed & & 3 & 1 & 4 \\
\hline & Normal & 10 & 36 & 18 & 64 \\
\hline Total & & 11 & 39 & 22 & 72 \\
\hline
\end{tabular}

\section{E2-Day 1}

I1-Day 1

Plantarflexed Dorsiflexed Normal Total

Plantarflexed

Dorsiflexed

2

Normal

23

Total

25

$\begin{array}{ccc}1 & 1 & 4 \\ 3 & 1 & 4 \\ 30 & 11 & 64 \\ 34 & 13 & 72\end{array}$

I2-Day 1

E1-Day 1

Plantarflexed

Dorsiflexed

Plantarflexed

5

Dorsiflexed

12

Normal

4

2

11

6

Total

21

19

\begin{tabular}{cr} 
Normal & Total \\
\hline 4 & 11 \\
16 & 39 \\
12 & 22 \\
32 & 72 \\
\hline
\end{tabular}

I2-Day 1

E2-Day 1

Plantarflexed Dorsiflexed

Plantarflexed

10

Dorsiflexed

9

Normal

Total

2

21

3

12

4

19

12

$13 \quad 34$

$\begin{array}{ll}7 & 13\end{array}$

E1-Day 1

E2-Day 1

Plantarflexed Dorsiflexed

Plantarflexed

4

Dorsiflexed

2

14

22

Normal

3

Total

11

39

32

72


Table D5. Interrater Distributions for Position Testing on Day 2.

\begin{tabular}{|c|c|c|c|c|c|}
\hline \multirow{2}{*}{ I1-Day 2} & \multicolumn{5}{|c|}{ I2-Day 2} \\
\hline & & Plantarflexed & Dorsiflexed & Normal & Total \\
\hline & Plantarflexed & 12 & 1 & 1 & 14 \\
\hline & Dorsiflexed & 3 & 1 & 1 & 5 \\
\hline & Normal & 28 & 8 & 17 & 53 \\
\hline Total & & 43 & 10 & 19 & 72 \\
\hline \multirow{5}{*}{ I1-Day 2} & & & E1-Day 2 & & \\
\hline & & Plantarflexed & $\overline{\text { Dorsiflexed }}$ & Normal & Total \\
\hline & Plantarflexed & 6 & 2 & 6 & 14 \\
\hline & Dorsiflexed & 2 & 1 & 2 & 5 \\
\hline & Normal & 18 & 19 & 16 & 53 \\
\hline Total & & 26 & 22 & 24 & 72 \\
\hline \multirow{6}{*}{ E2-Day 2} & & & I1-Day 2 & & \\
\hline & & Plantarflexed & Dorsiflexed & Normal & Total \\
\hline & Plantarflexed & 7 & 3 & 27 & 37 \\
\hline & Dorsiflexed & 2 & 2 & 12 & 16 \\
\hline & Normal & 5 & & 14 & 19 \\
\hline & & 14 & 5 & 53 & 72 \\
\hline Total & & & E1-Day 2 & & \\
\hline \multirow[t]{4}{*}{ I2-Day 2} & & Plantarflexed & Dorsiflexed & Normal & Total \\
\hline & Plantarflexed & 19 & 10 & 14 & 43 \\
\hline & Dorsiflexed & 2 & 4 & 4 & 10 \\
\hline & Normal & 5 & 8 & 6 & 19 \\
\hline \multirow[t]{2}{*}{ Total } & & 26 & 22 & 24 & 72 \\
\hline & & & I2-Day 2 & & \\
\hline \multirow[t]{4}{*}{ E2-Day 2} & & Plantarflexed & Dorsiflexed & Normal & Total \\
\hline & Plantarflexed & 25 & 2 & 10 & 37 \\
\hline & Dorsiflexed & 9 & 3 & 2 & 16 \\
\hline & Normal & 9 & 3 & 7 & 19 \\
\hline Total & & 43 & 10 & 19 & 72 \\
\hline \multirow{5}{*}{ E2-Day 2} & & & E1-Day 2 & & \\
\hline & & Plantarflexed & Dorsiflexed & Normal & Total \\
\hline & Plantarflexed & 12 & 12 & 13 & 37 \\
\hline & Dorsiflexed & 8 & 2 & 6 & 16 \\
\hline & Normal & 6 & 8 & 5 & 19 \\
\hline Total & & 26 & 22 & 24 & 72 \\
\hline
\end{tabular}


Table D6. Intrarater Reliability of First Ray Mobility Test.

\begin{tabular}{lcclcc}
\hline Examiner & $\begin{array}{c}\text { Agreement } \\
(\%)\end{array}$ & $\begin{array}{c}\text { Kappa } \\
(\mathbf{9 5 \%} \mathbf{C I})\end{array}$ & $\mathbf{P - V a l u e}$ & $\mathbf{K}_{\mathbf{m a x}}$ & $\begin{array}{c}\mathbf{K} / \mathbf{K}_{\max } \\
(\mathbf{\%})\end{array}$ \\
\hline I1 & 57 & 0.263 & $0.001^{* *}$ & .52 & 50.6 \\
I2 & 46 & 0.181 & $0.010^{*}$ & .48 & 37.7 \\
E1 & 40 & 0.069 & 0.403 & .74 & 9.3 \\
E2 & 52 & 0.000 & 0.838 & .83 & 00 \\
\hline
\end{tabular}

$\mathrm{I}=$ Inexperienced; $\quad \mathrm{E}=$ Experienced

$\mathrm{N}=72$

$* \mathrm{P} \leq 0.01$

$* * \mathrm{P} \leq 0.001$

Table D7. Intrarater Distributions for Mobility Testing.

\begin{tabular}{|c|c|c|c|c|c|}
\hline \multirow[b]{2}{*}{ I1-Day 1} & \multicolumn{5}{|c|}{ I1-Day 2} \\
\hline & & Hypermobile & Hypomobile & Normal & Total \\
\hline & Hypermobile & 4 & 1 & 2 & 7 \\
\hline & Hypomobile & & 9 & 3 & 12 \\
\hline & Normal & 8 & 17 & 28 & 53 \\
\hline Total & & 12 & 27 & 33 & 72 \\
\hline
\end{tabular}

I2-Day 2

I2-Day 1

Hypermobile

Hypomobile

Normal 9
Total

Hypermobile Hypomobile Normal Total

$\begin{array}{cccc}4 & 3 & 1 & 8 \\ 7 & 22 & 1 & 30 \\ 9 & 18 & 7 & 34 \\ 20 & 43 & 9 & 72\end{array}$

\section{E1-Day 2}

E1-Day 1

Hypermobile Hypomobile Normal Total

Hypermobile

Hypomobile

14

Normal

14

28

Total

\section{E2-Day 2}

E2-Day 1

Hypermobile Hypomobile Normal Total

Hypermobile

Hypomobile

Normal

6

7

10

23

$\begin{array}{ccc}4 & 6 & 16 \\ 5 & 13 & 25 \\ 8 & 13 & 31\end{array}$

Total

17

32

72


Table D8. Interrater Reliability of First Ray Mobility Test.

\begin{tabular}{lccccc}
\hline Examiner & $\begin{array}{c}\text { Agreement } \\
\mathbf{( \% )}\end{array}$ & $\begin{array}{c}\text { Kappa } \\
\mathbf{( 9 5 \%} \mathbf{C I})\end{array}$ & $\mathbf{P - V a l u e}$ & $\mathbf{K}_{\mathbf{m a x}}$ & $\begin{array}{c}\mathbf{K} / \mathbf{K}_{\max } \\
\mathbf{( \% )}\end{array}$ \\
\hline Day 1 & & & & & \\
I1 x I2 & 46 & 0.053 & 0.502 & .54 & 9.8 \\
I1 x E1 & 40 & 0.024 & 0.719 & .41 & 5.9 \\
I1 x E2 & 44 & 0.080 & 0.288 & .49 & 16.3 \\
I2 x E1 & 38 & 0.105 & 0.106 & .58 & 18.1 \\
I2 x E2 & 38 & 0.004 & 0.966 & .82 & 0.5 \\
E1 x E2 & 39 & 0.092 & 0.218 & .63 & 14.6 \\
& & & & & \\
Day 2 & & & & & \\
I1 x I2 & 42 & 0.133 & 0.061 & .51 & 26.1 \\
I1 x E1 & 42 & 0.036 & 0.644 & .77 & 4.7 \\
I1 x E2 & 35 & 0.109 & 0.178 & .67 & 16.3 \\
I2 x E1 & 46 & 0.216 & $0.003 *$ & .49 & 44.1 \\
I2 x E2 & 24 & 0.000 & 0.304 & .49 & 00 \\
E1 x E2 & 35 & 0.010 & 0.907 & .85 & 1.2 \\
\hline
\end{tabular}

$\mathrm{I}=$ Inexperienced; $\quad \mathrm{E}=$ Experienced

$\mathrm{N}=72$

* Indicates a significance of $p \leq 0.01$ 
Table D9. Interrater Distributions for Mobility Testing on Day 1.

\begin{tabular}{|c|c|c|c|c|c|}
\hline \multirow[b]{2}{*}{ I1-Day 1} & \multicolumn{5}{|c|}{ I2-Day 1} \\
\hline & & Hypermobile & Hypomobile & Normal & Total \\
\hline & Hypermobile & 2 & & 5 & 7 \\
\hline \multirow[b]{3}{*}{ Total } & Hypomobile & & 7 & 5 & 12 \\
\hline & Normal & 6 & 23 & 24 & 53 \\
\hline & & 8 & 30 & 34 & 72 \\
\hline \multirow{5}{*}{ I1-Day 1} & & & E1-Day 1 & & \\
\hline & & Hypermobile & Hypomobile & Normal & Total \\
\hline & Hypermobile & 3 & & 4 & 7 \\
\hline & Hypomobile & 4 & 3 & 5 & 12 \\
\hline & Normal & 26 & 4 & 23 & 53 \\
\hline Total & & 33 & 7 & 32 & 72 \\
\hline
\end{tabular}

E2-Day 1

I1-Day 1

Hypermobile

Hypomobile

Normal

Total

Hypermobile Hypomobi

$\begin{array}{cccc}2 & 1 & 4 & 7 \\ 1 & 7 & 4 & 12 \\ 13 & 17 & 23 & 53 \\ 16 & 25 & 31 & 72\end{array}$

E1-Day 1

I2-Day 1

Hypermobile Hypomobile Normal Total

Hypermobile

Hypomobile

Normal

5

13

15

Total

33

\section{I2-Day 1}

E2-Day 1

Hypermobile Hypomobile Normal Total

Hypermobile

Hypomobile

Normal

2
3
3

5

11

9

11

14

$14 \quad 31$

Total

8

30

34

\section{E1-Day 1}

E2-Day 1

Hypermobile

Hypomobile

Hypermobile

Hypomobile

Normal

\section{2}

5

9

16

Total

33

7

$18 \quad 31$

$32 \quad 72$


Table D10. Interrater Distributions for Mobility Testing on Day 2.

\begin{tabular}{|c|c|c|c|c|c|}
\hline \multirow[t]{4}{*}{ I1-Day 2} & \multicolumn{2}{|c|}{ I2-Day 2} & $\frac{\mathrm{y} 2}{\mathrm{mob}}$ & Normal & Total \\
\hline & Hypermobile & 5 & 7 & & 12 \\
\hline & Hypomobile & 5 & 19 & 3 & 27 \\
\hline & Normal & 10 & 17 & 6 & 33 \\
\hline Total & & 20 & 43 & 9 & 72 \\
\hline I1-Day 2 & & Hypermob & $\frac{\mathrm{ay} 2}{\mathrm{mob}}$ & Normal & Total \\
\hline & Hypermobile & 6 & 3 & 3 & 12 \\
\hline & Hypomobile & 4 & 10 & 13 & 27 \\
\hline & Normal & 18 & 6 & 9 & 33 \\
\hline Total & & 28 & 19 & 25 & 72 \\
\hline
\end{tabular}

E2-Day 2

I1-Day 2

Hypermobile

Hypomobile

Normal

Total
Hypermobile

6
8
9
23

Hypomobile Normal Total

$\begin{array}{ccc}1 & 5 & 12 \\ 8 & 11 & 27 \\ 8 & 16 & 33 \\ 17 & 32 & 72\end{array}$

\begin{tabular}{llcccc} 
I2-Day 2 & & Hypermobile & Hypomobile & Normal & Total \\
& Hypermobile & 12 & 2 & 6 & 20 \\
& Hypomobile & 11 & 17 & 15 & 43 \\
& Normal & 5 & & 4 & 9 \\
Total & & 28 & 19 & 25 & 72 \\
\hline
\end{tabular}

\section{E2-Day 2}

I2-Day 2

Hypermobile Hypomobile Normal Total

Hypermobile

Hypomobile

Normal

6

12

5

Total

\section{6}

9

2

17

$\begin{array}{ccc}6 & 8 & 20 \\ 9 & 22 & 43 \\ 2 & 2 & 9\end{array}$

\section{E2-Day 2}

E1-Day 2

Hypermobile Hypomobile Normal Total

Hypermobile

Hypomobile

Normal

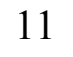

6

6

23

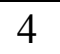

4

9

32

72

Total

17

$\begin{array}{ccc}13 & 28 \\ 9 & 19 \\ 9 & 25\end{array}$


Figure D1. First Ray Position Results (Day 1).

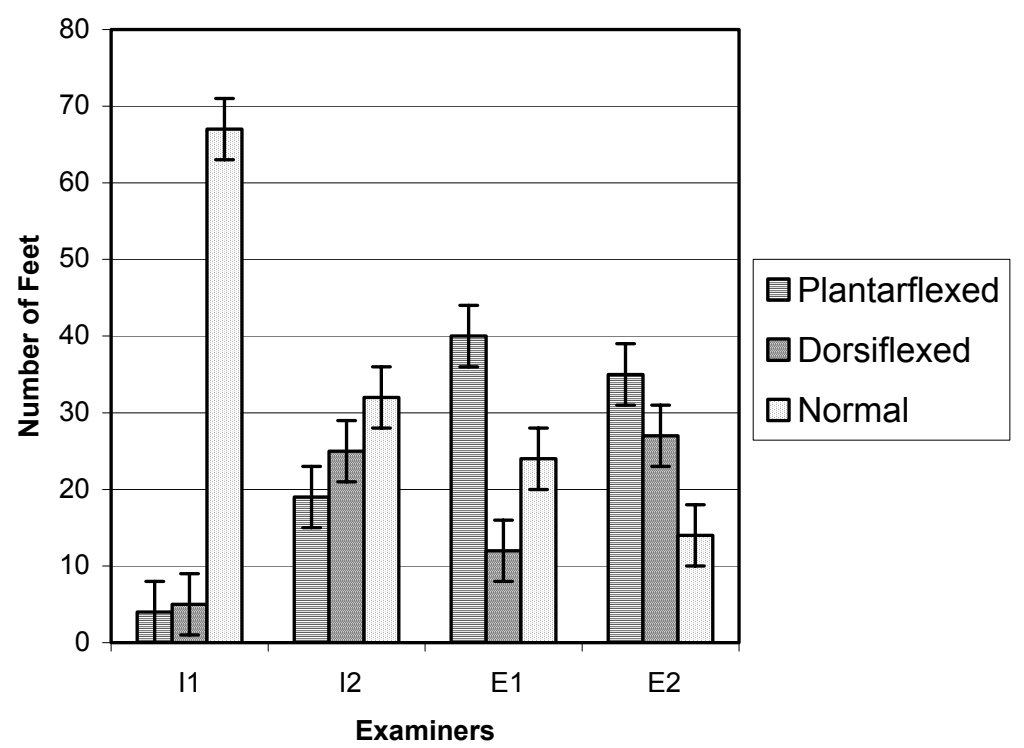

Figure D2. First Ray Position Results (Day 2).

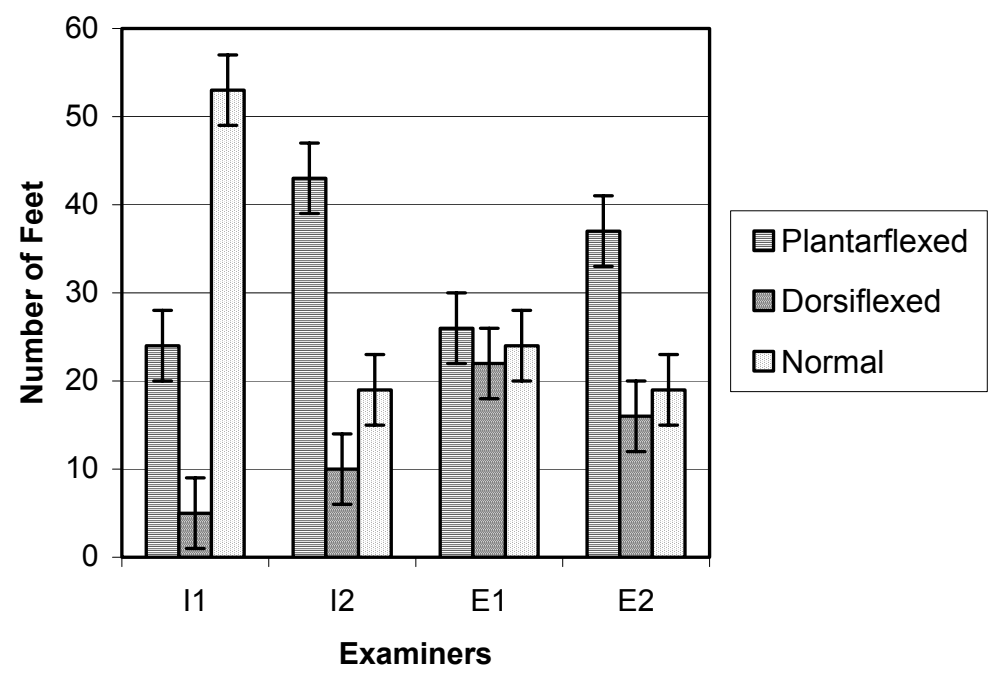


Figure D3. First Ray Mobility Results (Day 1).

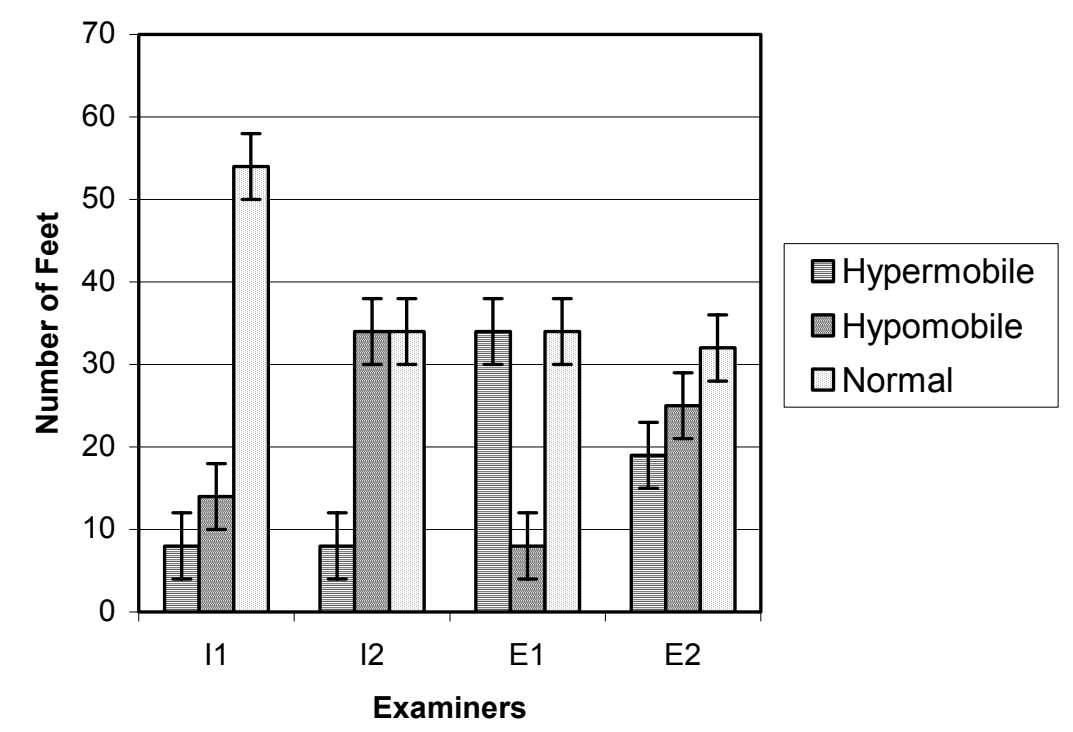

Figure D4. First Ray Mobility Results (Day 2).

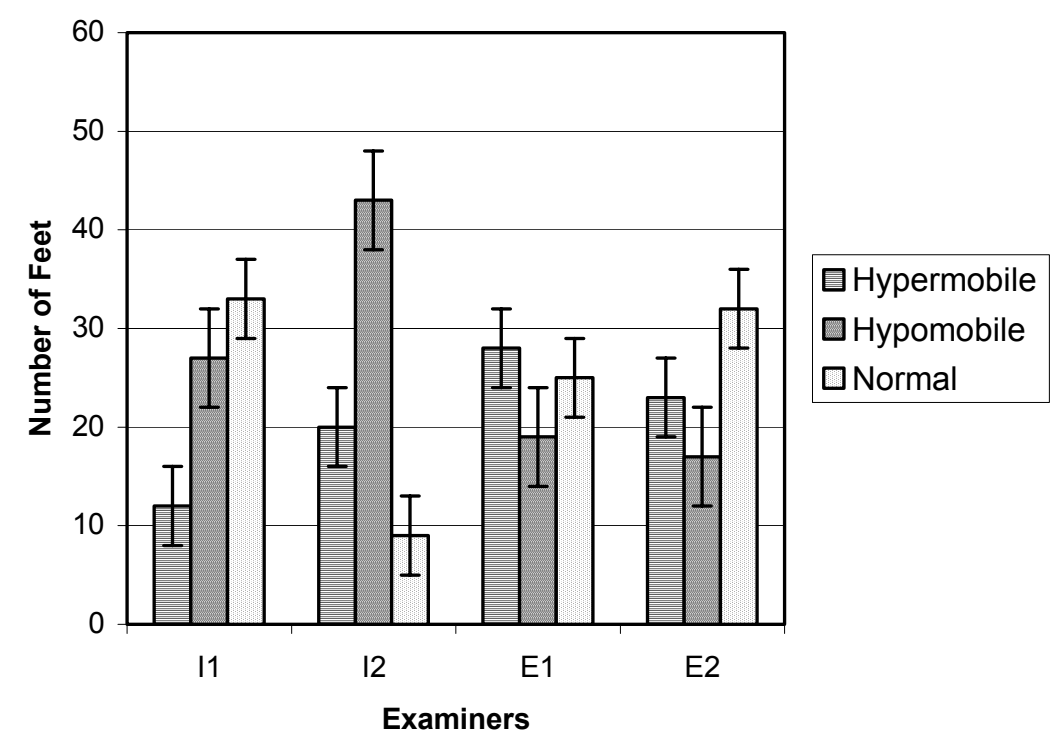




\section{APPENDIX E \\ RECOMMENDATIONS FOR FUTURE STUDIES}

1. Using the first ray mobility measuring device as a gold standard, determine validity of Root's manual first ray mobility techniques.

2. Glasoe's method should be evaluated for reliability and validity of first ray mobility and position measurements.

3. A study comparing Glasoe's and Rottt's techniques for reliability and validity.

4. For experienced examiners, use foot specialists, physical therapists, or athletic trainers working in clinics to ensure that these measurements are common for the examiner. This will ensure that your examiners are truly experienced.

5. Have a more in-depth session or longer session for teaching and practicing the technique.

6. To differentiate examiners, give two examiners an in-depth continuing education course while the other two examiners only receive a video and notes on the measurement to study on their own. Then compare reliability of the examiners.

7. Ensure that for each set of examiners, one is female and the other is male. This may decrease any bias that males or females are better than the other.

8. Examining EMG measurements or strength measurements using an isokinetic machine on the peroneus longus, anterior tibialis, and posterior tibialis muscles of subjects to determine which muscles may be affected or affect the position and mobility of the first ray. This can be performed weight-bearing to determine the muscle weaknesses during the gait cycle. 


\section{ADDITIONAL REFERENCES}

31. Kelso SF, Richie DH, Cohen IR, Weed JH, Root M. Direction and range of motion of the first ray. J Am Pod Assoc. 1982;72(12):600-605.

32. Prieskorn DW, Mann RA, Fritz G. Radiographic assessment of the second metatarsal: measure of first ray hypermobility. Foot Ankle Int.

1996;17(6):331-3.

33. Birke JA, Franks BD, Foto JG. First ray joint limitation, pressure, and ulceration of the first metatarsal head in diabetes mellitus. Foot Ankle Int. 1995;16(5):277-283.

34. Klaue K, Hansen ST, Masquelet AC. Clinical, Quantitative assessment of first tarsometatarsal mobility in the sagittal plane and its relation to hallux valgus deformity. Foot Ankle. 1994;15(1):9-12.

35. Morton DJ. Structural factors in static disorders of the foot. Am J Surg. 1930;9(2):315-328.

36. Glasoe WM, Allen MK, Kepros T, Stonewall L, Ludwig PM. Dorsal first ray mobility in women athletes with a history of stress fracture of the second or third metatarsal. J Orthop Sports Phys Ther. 2002;32(11):560-565.

37. Rush SM, Christensen JC, Johnson CH. Biomechanics of the first ray. Part II. Metatarsus primus varus as a cause of hypermobility. A three-dimensional kinematic analysis in a cadaver model. J Foot Ankle Surg. 2000;39(2):68-77.

38. Whittle M. Gait Analysis: an introduction. Third Edition. ButterworthHeinemann. Woburn, MA, 2002.

39. Rodgers MM. Dynamic biomechanics of the normal foot and ankle during walking and running. Phys Ther. 1988;68(12):1822-1830.

40. Donatelli R. Normal biomechanics of the foot and ankle. J Orthop Sports Phys Ther. 1985;7(3):91-5.

41. Sarrafian SK. Anatomy of the Foot and Ankle. Descriptive, Topographic, Functional. J.B. Lippincott Company. Philadelphia, PA, 1983.

42. Stokes IAF, Hutton C, Stott JRR. Forces acting on the metatarsals during normal walking. J Anat. 1979;129(3):579-90.

43. Ray R. First metatarsocuneiform arthrodesis: Technical considerations and technique modification. J Foot Ankle Surg. 2002;41(4):260-72. 
44. Romash MM, Fugate D, Yanklowit B. Passive motion of the first metatarsal cuneiform joint: Preoperative assessment. Foot Ankle. 1990;10(6):293-8.

45. Scranton PE, Rutkowski R. Anatomic variations in the first ray: Part II. Disorders of the sesamoids. Clin Orthop. 1980;151:257-264.

46. Hicks JG. The mechanics of the foot. I. The joints. J Anat. 1953;87:345-57.

47. Myerson MS, Badekas A. Hypermobility of the first ray. Foot Ankle Clin. 2000;5(3):469-83.

48. Wanivenhaus A, Pretterklieber M. First tarsometatarsal joint: anatomical biomechanical study. Foot Ankle. 1989;9(4):153-7.

49. Ouzounian TJ, Shereff MJ. In vitro determination of midfoot motion. Foot Ankle. 1989;10(3):140-6.

50. Meyer JM, Tomeno B, Burdet A. Metatarsalgia due to insufficient support by the first ray. Int Orthop. 1981;5:193-201.

51. Coughlin MJ, Shumas PS. Hallux valgus in men Part II: First ray mobility after bunionectomy and factors associated with hallux valgus deformity. Foot Ankle Int. 2003;24(1):73-78.

52. Scranton PE, Rutkowski R. Anatomic variations in the first ray: Part I. Anatomic aspects related to bunion surgery. Clin Orthop. 1980;151:244-256.

53. Bouysset M, Tebib J, Noel E, et al: Rheumatoid flat foot and deformity of the first ray. J Rheumatol. 2002;29:903-5.

54. Ehrat M, Edwards J, Hastings D, Worrell T. Reliability of assessing patellar alignment: The A angle. J Orthop Sports Phys Ther. 1994;19(1):22-27.

55. Sell KE, Verity TM, Worrell TW, Pease BJ, Wigglesworth J. Two measurement techniques for assessing subtalar joint position: A reliability study. J Orthop Sports Phys Ther. 1994;19(3):162-167.

56. Gibson MH, Goebel GV, Jordan TM, Kegerreis S, Worrell TW. A reliability study of measurement techniques to determine static scapular position. $J$ Orthop Sports Phys Ther. 1995;21(2):100-106.

57. Neylon TA, Johnson BA, Laroche RA. Use of the lapidus bunionectomy in the first ray insufficiency. Clin Pod Med Surg. 2001;18(2):365-75. 
58. Lombardi CM, Silhanek AD, Connolly FG, Dennis LN. The effect of first metatarsophalangeal joint arthrodesis on the first ray and the medial

longitudinal arch: a radiographic study. J Foot Ankle Surg. 2002;41(2):96-103. 